\title{
UHMWPE for biomedical applications: performance and functionalization.
}

AVINASH PATIL, N., NJUGUNA, J. and KANDASUBRAMANIAN, B. 


\section{Journal Pre-proofs}

UHMWPE for Biomedical Applications: Performance and Functionalization

Nikhil Avinash Patil, James Njuguna, Balasubramanian Kandasubramanian

PII:

S0014-3057(19)32201-3

DOI: https://doi.org/10.1016/j.eurpolymj.2020.109529

Reference: EPJ 109529

To appear in:

European Polymer Journal

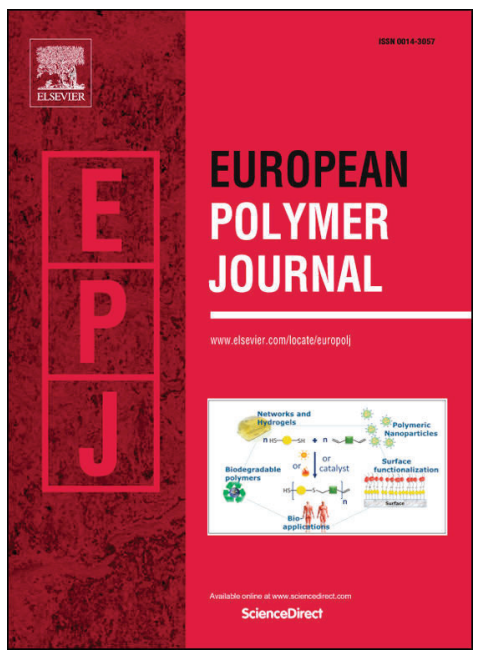

Received Date:

26 October 2019

Revised Date:

14 January 2020

Accepted Date:

17 January 2020

Please cite this article as: Avinash Patil, N., Njuguna, J., Kandasubramanian, B., UHMWPE for Biomedical Applications: Performance and Functionalization, European Polymer Journal (2020), doi: https://doi.org/ 10.1016/j.eurpolymj.2020.109529

This is a PDF file of an article that has undergone enhancements after acceptance, such as the addition of a cover page and metadata, and formatting for readability, but it is not yet the definitive version of record. This version will undergo additional copyediting, typesetting and review before it is published in its final form, but we are providing this version to give early visibility of the article. Please note that, during the production process, errors may be discovered which could affect the content, and all legal disclaimers that apply to the journal pertain.

(C) 2020 Published by Elsevier Ltd. 


\title{
UHMWPE for Biomedical Applications: Performance and Functionalization
}

\author{
Nikhil Avinash Patil ${ }^{\mathrm{a}}$, James Njuguna ${ }^{\mathrm{b}}$ Balasubramanian Kandasubramanianc, ${ }^{\mathrm{c}}$ \\ aDepartment of Fibres and Textile Processing Technology, Institute of Chemical Technology, \\ Mumbai, India
}

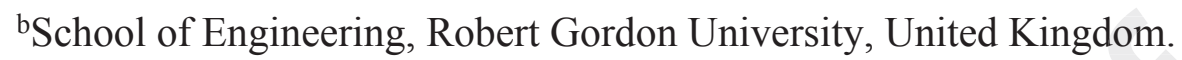

${ }^{\mathrm{c} N a n o ~ T e x t u r i n g ~ L a b o r a t o r y, ~ D e p a r t m e n t ~ o f ~ M e t a l l u r g i c a l ~ a n d ~ M a t e r i a l s ~ E n g i n e e r i n g, ~}$ Defence Institute of Advanced Technology (DU), Ministry of Defence, Girinagar, Pune, India.

*Corresponding Author E-mail: meetkbs@gmail.com

\begin{abstract}
According to a survey conducted by Grand View Research, the market demand for medical grade UHMWPE has raise remarkably from 60.9 kilotons up to 204.8 kilotons during 20152024 valued at $\$ 1.36$ billion (USD) with a compound annual growth rate of $15 \%$. There are various materials available for medical implants comprising of metals, ceramics and polymers among them UHMWPE has been used widely. The wide impact of UHMWPE in medical field is due it's superior biocompatibility, chemical resistance, low wear volume $\left(0.68 \mathrm{~mm}^{3}\right)$, ultimate tensile strength $(41.3 \mathrm{MPa})$, low coefficient of friction [In dry condition (0.12-0.15)] and high crystallinity (more than 90\%). However, wear debris, oxidative degradation due to generation of free radicals when subjected to irradiation with gamma rays and low ageing of implant are some critical problems observed in UHMWPE based implants in human body. These severe problems have been resolved using various innovative methodologies to enhance the properties of UHMWPE, comprising of surface modification techniques for pure UHMWPE as well as composite reinforced UHMWPE. The enhancement
\end{abstract}


in properties of pure UHMWPE is achieved using electron beam or atmospheric cold plasma treatment. The reinforced composites are majorly developed by reinforcement of materials such as hydroxyapatite, Multi walled carbon nanotubes, Vitamin E ( $\alpha$-tocopherol), graphene oxide, DLC films, Gallic acid and Dodecyl gallate along with base UHMWPE matrix material. Based on the recent studies, Comparative study of these functionalization techniques along with the ameliorated surface or bulk properties along with it's diverse application in medical implant fields (Total hip arthroplasty, joint implants, bone tissue engineering) has been discussed extensively. Descriptive study of pure UHMWPE along with it's composite to functionalize the properties of the medical implants has been included in this review along with it's future scope succeeding the review.

Keywords: UHMWPE, biocompatibility, tribological properties, composites, total hip arthroplasty, joint implants, bone tissue engineering, medical applications.

\section{Introduction}

Global medical implant industry has been driven extensively due to advancements in surgical technology, acceptance of advance material implants (total hip arthroplasty[1], artificial joint implants[2], bone tissue engineering[3-11] and spine implants, etc.) as well as increment in ageing of population (according to the United Nations report, 13\% of the global population is above the age of 60 years and it is increasing at a rate of $3 \%$ per year[12]). Among the various available materials (polymers[13-16], metals[17]'[18], and ceramics[19]'[20]) in practice, medical grade ultra-high molecular weight polyethylene (UHMWPE) is widely used polymer for manufacturing of medical implants[21]'[22]. UHMWPE is a homo-polymer consisting of ethylene as monomeric units, responsible for exhibiting highly cross-linked structure. The structure further results in higher molecular weight polymer having molecular weight ranging between of $3.5 \times 10^{6} \mathrm{~g} / \mathrm{mol}$ to $6 \times 10^{6} \mathrm{~g} / \mathrm{mol}$, comprising of various forms such 
as fibres, plates or tubular structure depending upon the variety of medical grade UHMWPE used for diverse medical applications[23]. UHMWPE is a highly oriented thermoplastic fibre having highly crystalline structure (exhibiting crystallinity more than 90\%), along with it's good biocompatibility[24,25], chemical inertness[26], High ultimate tensile strength (43.2 MPa, for a medical grade UHMWPE Lumber L4000) [27], low wear volume $\left(0.68 \mathrm{~mm}^{3}\right.$, for a medical grade UHMWPE Lumber L4000)[27], low coefficient of friction and low wear rate (0.15-0.2 mm/year) [28] which is responsible for it's numerous applications in biomedical applications.

The limitation of UHMWPE for medical applications is due to it's low melting point $\left(130^{\circ} \mathrm{C}-136^{\circ} \mathrm{C}\right)$, whereas limitations can be overcome by reinforcing with composite materials such as carbon nanotubes. The another limitation of UHMWPE is formation of free radicals when subjected to gamma irradiation, which are susceptible to react with oxygen resulting in breakage of polymeric chains as well as deteriorating crystalline portion of the polymeric material when exposed for longer duration, the formation of free radicals is usually avoided by reinforcing of antioxidants such as vitamin E [29,30]. The ester and acid formation may take place due to components of oxidative degradation of biomedical implants in the body and a possibility of hydroperoxide formation is recognized by the study of the UHMWPE sterilized with gamma rays[31]. UHMWPE exploited as a linear material between metal-metal femoral head leads to significant wear and failure of the material, whereas the resulting wear debris by friction between the two components cause inflammatory reactions which further results in osteolysis[21] and loosening of medical implant[32,33]. The high wear rate of medical implants is origin to biomechanics, impingement, and loosening of biomedical implants used in joints and hip arthroplasty. The primary solution to these problems is usage of highly cross-linked ultra-high molecular weight polyethylene which 
results in minimizing wear debris of the material, which eventually helps to reduce osteolysis.[34]'[35]

These limitations of UHMWPE in biomedical applications can be overcome by surface modification of virgin UHMWPE or reinforcement of base UHMWPE material with ceramic/composites. In this review we will discuss two ways for modifications in UHMWPE for biomedical applications

(1) surface modification of pure UHMWPE by treatment using electron beam[36], cold atmospheric plasma in presence of air[37] or carbon ion immersion

(2) Reinforcement of UHMWPE matrix with composite such as hydroxyapatite[38-40], multi-walled carbon nanotubes[41], vitamin E ( $\alpha$ - tocopherol)[42], nanographene oxide, diamond-like carbon (DLC) films, gallic acid (GA) and dodecyl gallate (DG), nanostructured zirconia on titanium spheres coupled with UHMWPE, vinyl triethoxysilane which acts as a coupling agent, etc. These modifications in UHMWPE matrix by reinforcing composite results in improved surface and bulk properties such as low coefficient of friction, low wear rate, high tensile strength, biocompatibility, oxidation resistance, etc.

The functionalization of pure medical grade UHMWPE is achieved by surface treatment of polymeric material with an electron beam in presence of air, which results in enhancement of the surface properties of polymer. SEM images of the functionalized polymer demonstrates the concealed porous structure on surface of polymer, resulting in increased surface roughness evolving it's application in bone implants [43]. In another process the properties are improved by surface treatment of UHMWPE with cold atmospheric plasma (CAP), where the CAP-treated UHMWPE shows optimized wear resistance enabling it's application in prosthesis, along with the improved adhesion of material essential during osseointegration[44]. 
Alternative approach for functionalization of UHMWPE is by implementing reinforcement of composites material with the base matrix material, which combines to amend the properties of substrate enabling the utilization of material in prosthesis or joint implants. The reinforcing composite material majorly comprises of hydroxyapatite, multiwalled carbon nanotubes (MWCNTs), vitamin E ( $\alpha$ - tocopherol), nanographene oxide, DLC films reinforced by sol-gel process, melt extrusion, plasma treatment, injection moulding etc. which resulted in formation of substrate showcasing modified surface and bulk properties (These has been concluded after a comparative study of SEM images obtained for composite reinforced material and untreated base material sample). The reinforced material imparts high strength, low coefficient of friction, ameliorated wear resistance and biocompatibility where the functionalized material has diverse application in biomedical applications, majorly focused on of total hip arthroplasty, joint implants, bone tissue engineering, and dental applications.

This review discusses about the synthesis of medical grade ultra-high molecular weight polyethylene along with various methodologies implemented for functionalization of pure UHMWPE and composite reinforced UHMWPE exhibiting numerous applications in biomedical field (Figure 1). The study of various possible alterations available for modifications in UHMWPE has been discussed elaborately to provide a clear vision regarding the research methodology to be implemented for functionalization of UHMWPE material, based on the required properties for implant specific application. The statistical data analysis for ultimate tensile strength, coefficient of friction, wear rate and properties such as biocompatibility, chemical resistance, hydrophilicity or hydrophobicity has been discussed. 


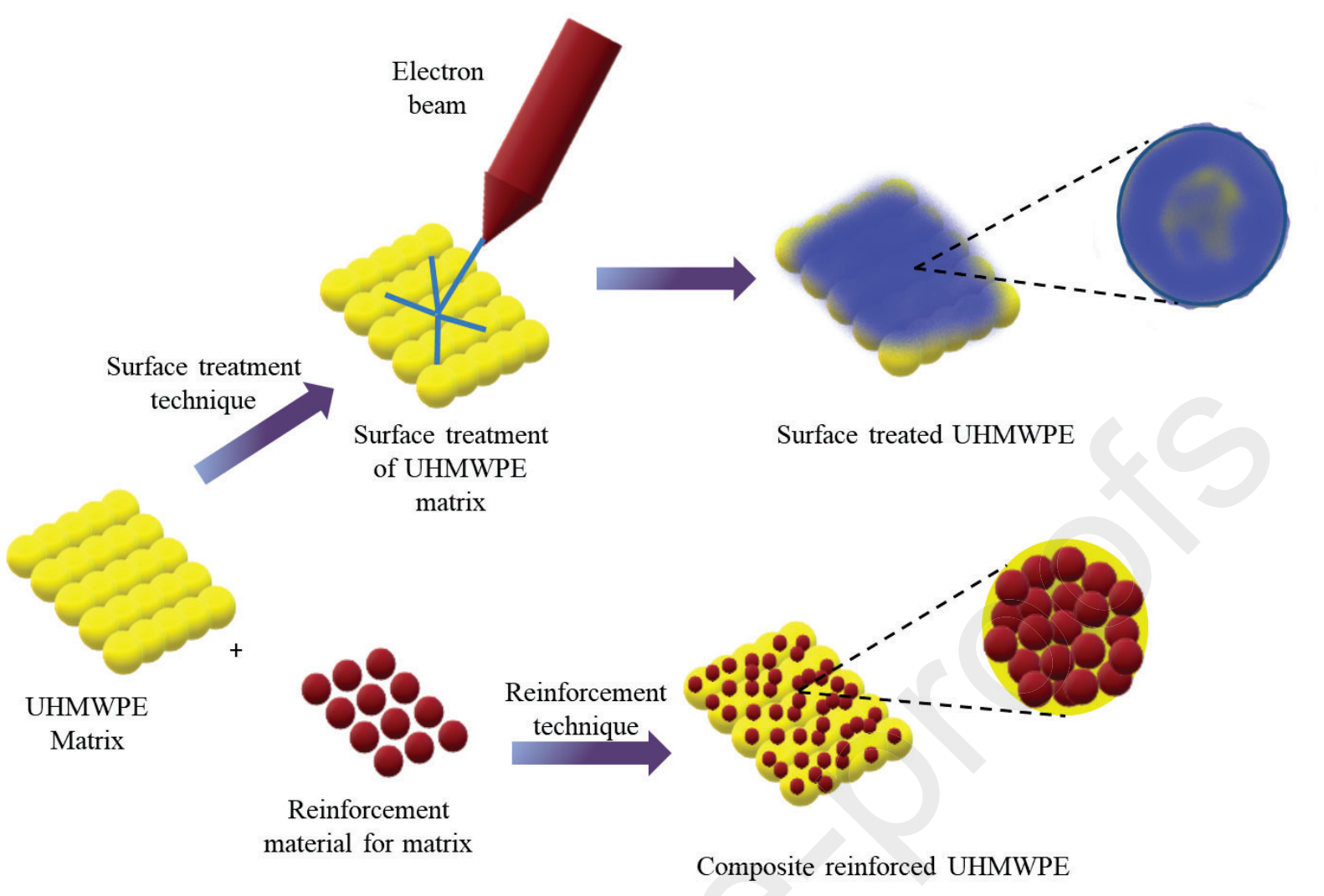

Figure 1: Functionalization methodology of medical grade UHMWPE

\section{Synthesis of UHMWPE}

UHMWPE is a thermoplastic polymer made up of polyethylene, it is composed of extremely long chains polyethylene which is responsible for transferring load effectively and providing a polymer backbone by strengthening the intermolecular interactions. This polymer backbone is beneficial for providing a tough material, where UHMWPE is recorded as the thermoplastic material having highest impact strength. The degree of polymerisation of UHMWPE is based on it's end applications, in case of orthopaedic applications the degree of polymerisation is observed within range of 71,000 - 214,000 with molecular weight ranging between 2 - 6 million $\mathrm{g} / \mathrm{mole}[23]$. UHMWPE is a linear and semi-crystalline polymer, consisting of two phases known as crystalline and amorphous phases. The crystalline phase is mainly composed of chains folded into highly oriented lamellae with crystals having 
orthorhombic structure[45]. The lamellae are $10 \mathrm{~nm}-50 \mathrm{~nm}$ thick and $10 \mu \mathrm{m}-50 \mu \mathrm{m}$ long, oriented randomly within the amorphous phase with tie molecules linking individual lamellae to one other[46]. The chemical structure for UHMEPW is as follows-

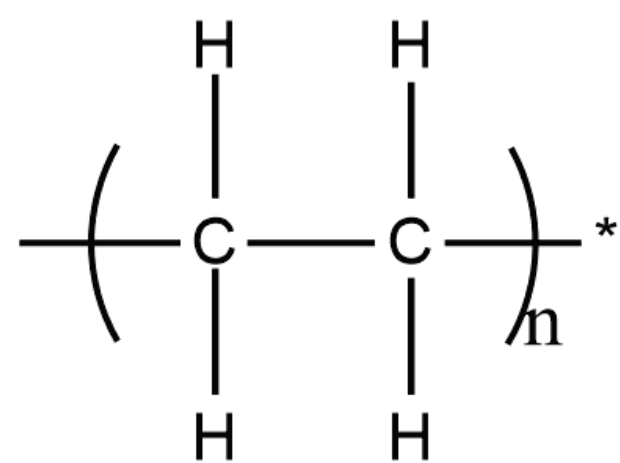

According to the statistical data received after accomplishment of research on UHMWPE in medical implants, the quality of medical grade UHMWPE plays a vital role in controlling wear properties of the medical implant. The data emphasizes on better clinical results as well as improved creep resistance exhibited by compression molded UHMWPE when compared with the other techniques [47]. In the recent market study of biomedical implant, GUR1050 extruded rod and GUR 1020 compression molded sheets are majorly used UHMWPE for orthopaedic applications in medical application[48]. The statistical analysis regarding the average molecular weight and calcium stearate content in commercial forms of medical grade UHMWPE is tabulated in table 1.

Table 1: Molecular weight analysis of commercial medical grade UHMWPE[48]

\begin{tabular}{|c|c|c|c|}
\hline Sample & Process & $\begin{array}{c}\text { Average molecular } \\
\text { weight }\left(10^{6} \mathrm{~g} / \mathrm{mol}\right)\end{array}$ & $\begin{array}{c}\text { Maximum calcium stearate } \\
\text { concentration(ppm) }\end{array}$ \\
\hline GUR 1050 & Extruded rod & $5.5-6$ & 75 \\
\hline GUR 1020 & $\begin{array}{c}\text { Compression } \\
\text { molding }\end{array}$ & 3.5 & 75 \\
& & & \\
\hline
\end{tabular}


The commercial level polymerization of UHMWPE was first introduced by Ruhrchemie AG (an industry originated in northern german region) during 1950's, which further came into research. In 1953 Ruhrchemie AG along with some chemists in Max-Plank Institute found out a brown and wet mass of a product that they declare as the novel form of evolved polyethylene manufactured at low pressure conditions. The materialistic importance of this product was appreciated considering the dangers in high pressure polymerization, which was further developed by Ruhrchemie AG in 1955's and the product was presented commercially in K55, a polymer trade scientific exhibition (Figure 2). Since then commercial production of UHMWPE powder has been started by Ruhrchemie (currently known as Celanese, which now happens to be a fortune 500 global technology and speciality chemicals manufacturing company) using ziegler's process[49].

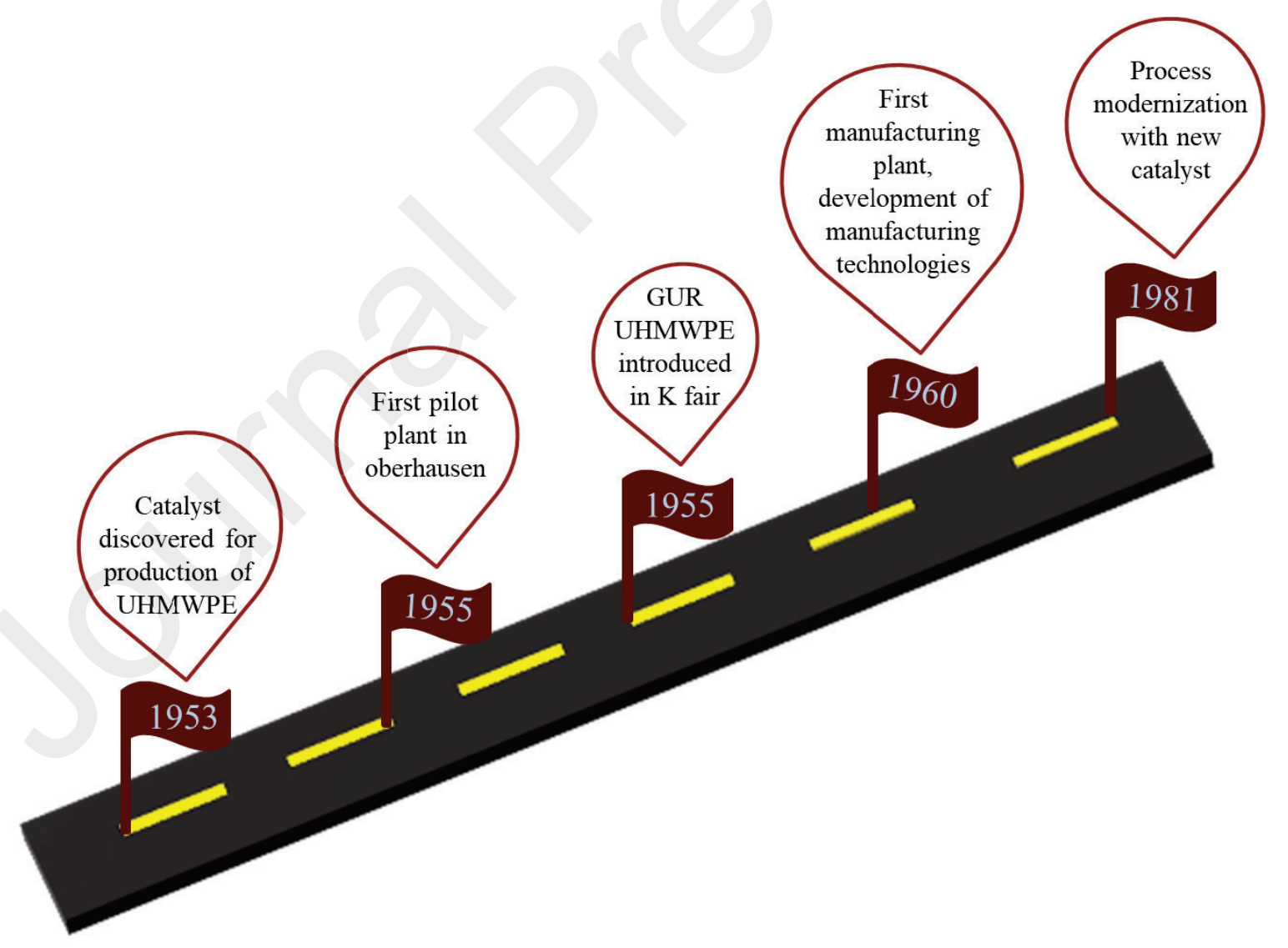

Figure 2: History of GUR UHMWPE 
The main components for manufacturing of UHMWPE are ethylene (a reactive gas), hydrogen, and titanium tetra chloride (acts as a catalyst), whereas the polymerization process is carried out in a solvent used for mass transfer as well as heat transfer (Figure 3). The ingredients used during polymerization process demands a specialized production plant due to presence of volatile components and potentially hazardous chemicals. Considering these circumstances while processing, various modifications has been done with use of titanium tetra chloride (catalyst) as it is a deciding factor while manufacturing of white UHMWPE with enhanced purity.

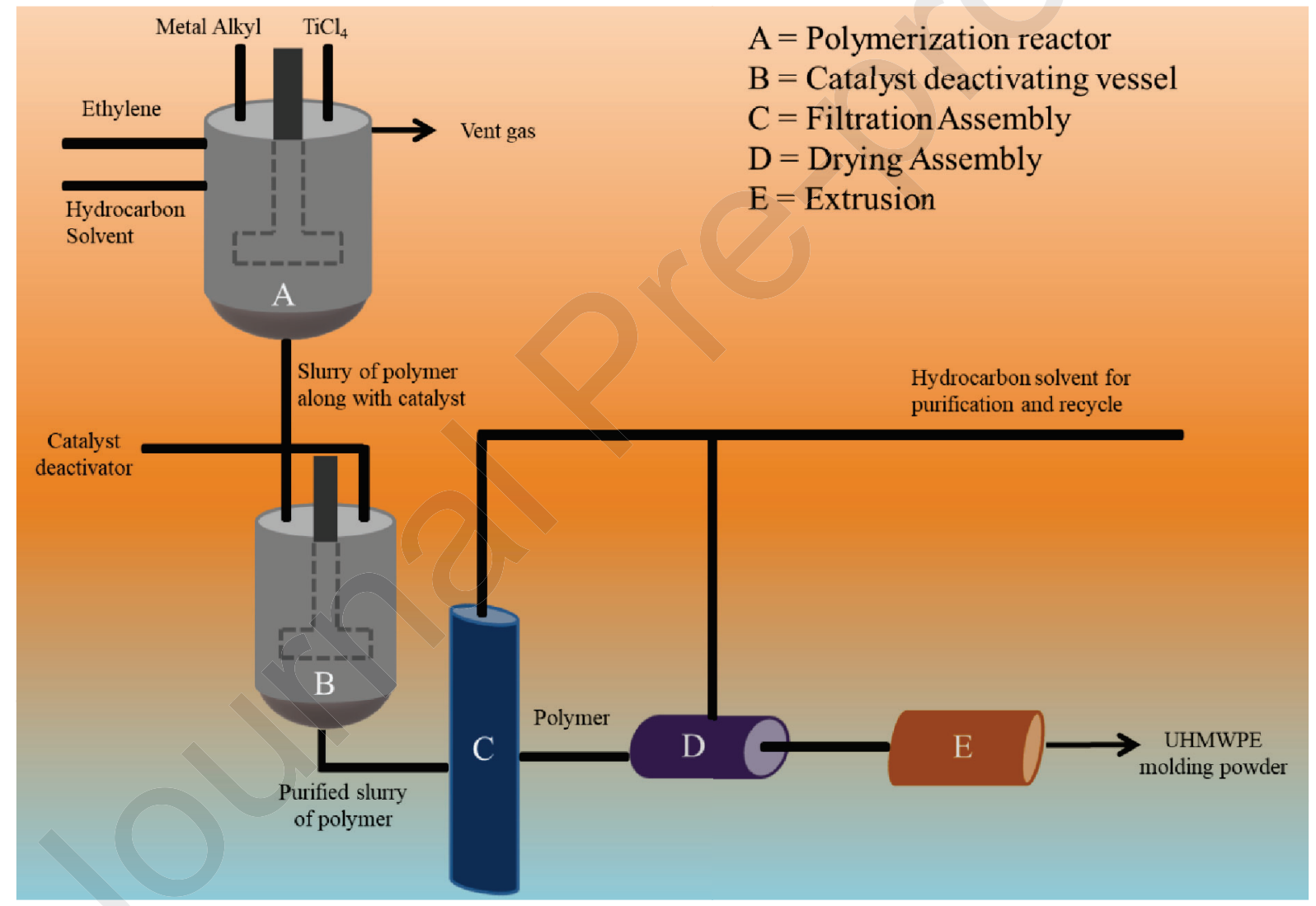

Figure 3: Zeigler process for medical grade UHMWPE manufacturing.

UHMWPE is manufactured in powder form and must be integrated at high temperature and pressure due to it's high melt viscosity, the consolidation is done in form of continuous sheets or rods by compression molding ( Figure 4) and ram extrusion process ( Figure. 5), as 
other conventional process cannot be implemented considering the high melt viscosity of UHMWPE. The consolidation process is governed by self-diffusion mechanism whereby the UHMWPE chains affiliate together at a molecular level using precise combination of time, temperature and pressure determining various properties of compression molded and extrusion stock UHMWPE[50,51], namely strength, porosity, surface roughness, etc. The inter granular diffusion kinetics of UHMWPE chains are promoted by propinquity of interfaces at high pressure conditions and thermally activated mobility of polymer chains at high temperature, as the process demands high contact time at prescribed high temperature and pressure conditions resulting in migration of molecular chains across grain boundaries. In case of the molding process, the pressure and temperature conditions are usually adjusted to about $230^{\circ} \mathrm{C}$ and $10 \mathrm{MPa}[19]$, whereas depending upon the desired properties of the material the parameters can be altered. The ultrastructure of the processed UHMWPE can be observed using optical or scanning electron microscopy according to the standardized technique prescribed by ASTM F648, which involves micro-toming of thin films and studying them under optical microscopy, preferably in presence of dark conditions[22]. However, the spotting of grain boundary in calcium stearate material is strenuous to detect. The visualization of grain boundaries can be achieved by freezing UHMWPE sample in liquid nitrogen and then fracturing the sample in frozen condition[52]. The ultrastructure of UHMWPE can be illustrated by intense study of freeze-fractured or etched UHMWPE surfaces using scanning electron microscopy. Consolidation defects may be observed if proper temperature, pressure and contact time is not provided for the consolidation process, defects are majorly noticed due to improper fusing of neighbouring resin particles during the compression molding process[49]. The inspection of medical grade UHMWPE can be achieved by non-destructive methods like laser candling and ultrasound, which doesn't require standardization during implementation for inspection of consolidation defects in the 
sample. The compression molded sheet of GUR 1020 and GUR 1050 are commercially produced by panies and MediTech, Celanese was also the producer of compression molded UHMWPE but they stopped the production by compression molding process in 1994 . The compression molding assembly used by MediTech consist of the two molds having dimensions of $1 \times 2 \mathrm{~m}$ in a single press cycle (Figure 4$)$.

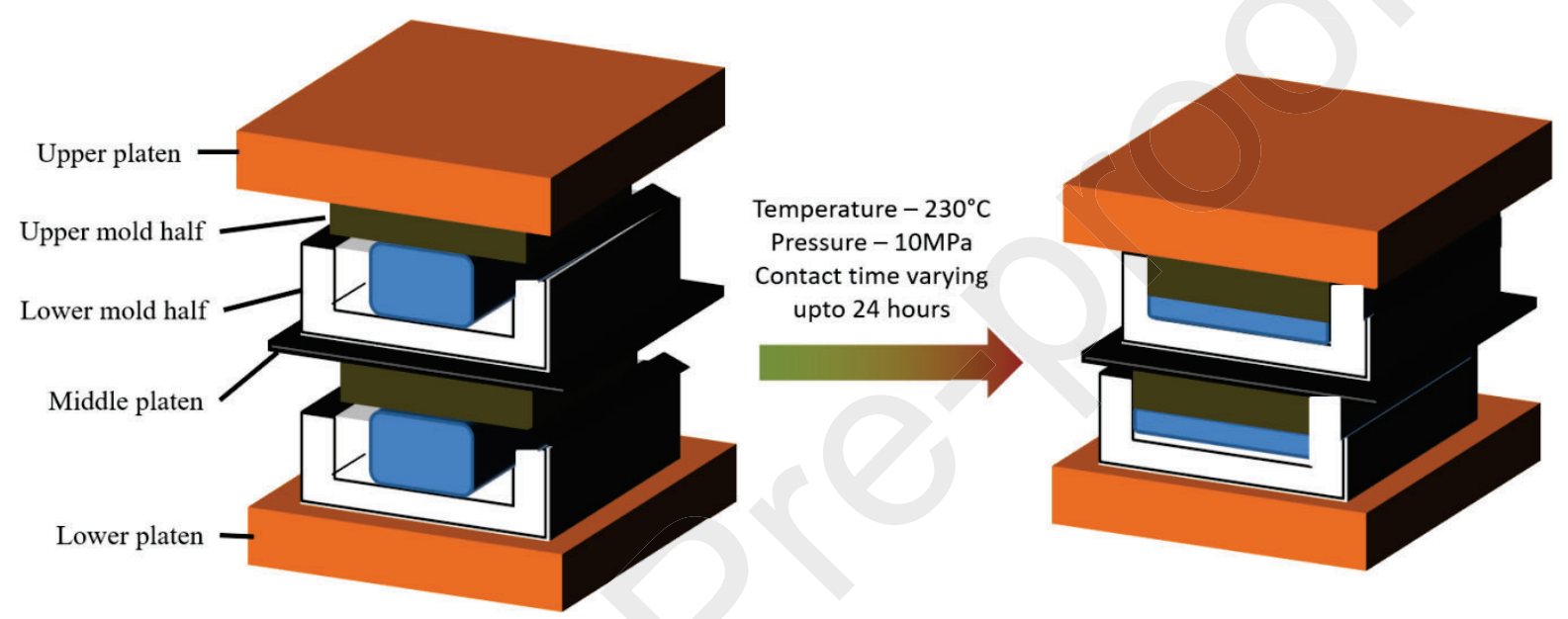

Figure 4: Compression molding assembly for 2 sheets

In UHMWPE manufacturing using ram extrusion process UHMWPE powder is fed continuously into extruder, attached to a hopper which allows the powder to fed into heating chamber, a horizontal reciprocating ram, a heated die and an outlet. UHMWPE is maintained under pressure by ram as well as back pressure exerted by molten UHMWPE, the exertion of back pressure is due to frictional forces of molten resin against the heated die surface. The UHMWPE rods are cooled after being extruded, and obtained in the outlet using a series of electric heating mantles ( Figure 5). The various sizes of UHMWPE rods are available using extrusion, generally ranging from $20 \mathrm{~mm}$ to $80 \mathrm{~mm}$ in diameter but can be produced up to diameter of 12 inches. The increase in diameter of UHMWPE rods results in drastic increase in cooling time of the rods as production rates are generally measured in millimetre per 
minute. The medical grade UHMWPE by ram extrusion process is commercially manufactured by MediTech and Westlake plastics. Medical grade extruder used during the process is generally recommended to keep in clean room to avoid the possibility of extra impurities while processing.

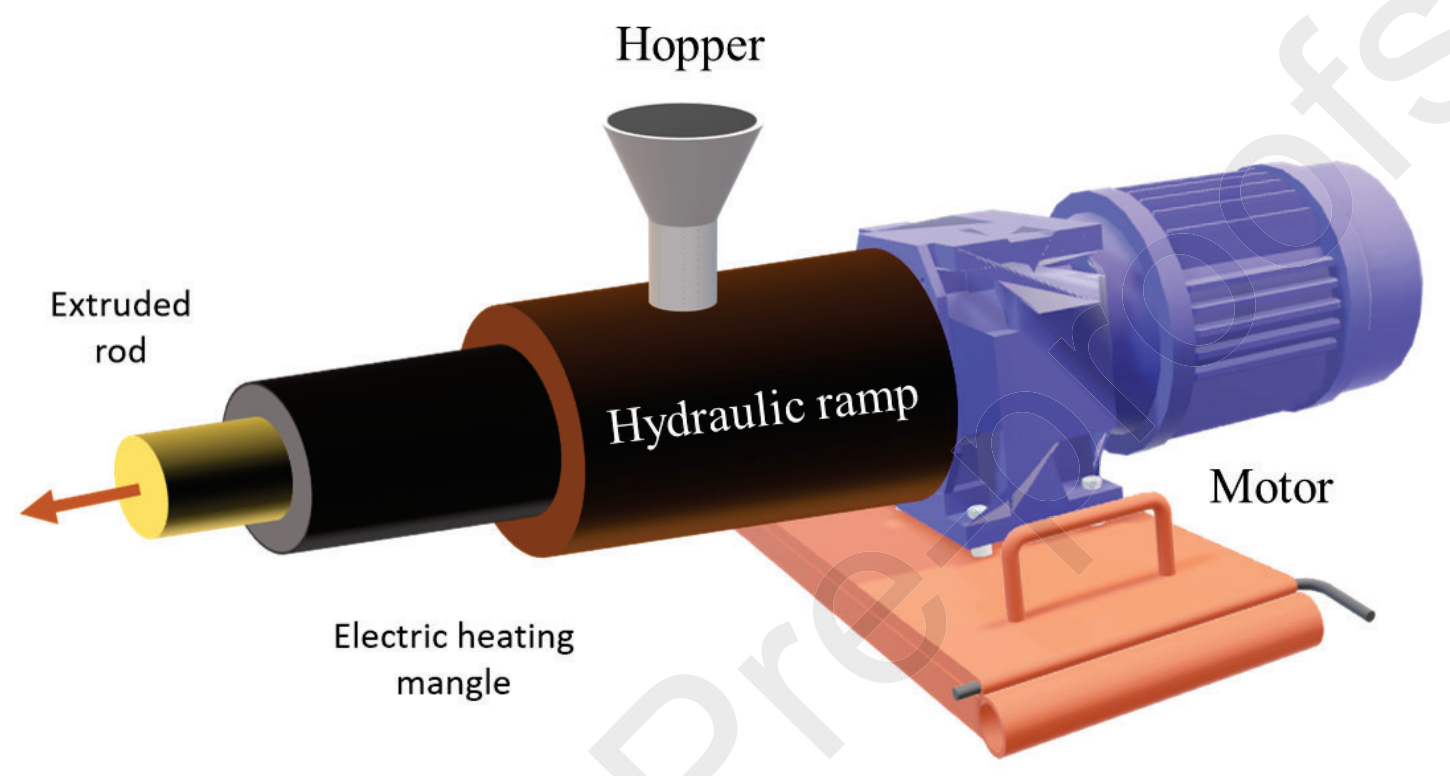

Figure 5: Ram extrusion process for UHMWPE manufacturing

Depending upon the various requirements of the medical grade UHMWPE powder specified in ASTM standard F648 and ISO standard 5834-1, the medical grade UHMWPE resins are classified in type 1, type 2, type 3. Depending upon the producer, molecular weight, trace impurities of aluminium, chlorine, titanium and residual traces of catalyst during the processing are determined, whereas ash content depends upon the storage conditions and handling of UHMWPE powder after execution of polymerization process ( in table 2). According to recent market study, Celanese is producer of type 1 and type 2 GUR resin with the commercial name as GUR 1020 and GUR 1050 sequentially compared in table 2.

Table 2: Requirement for medical grade UHMWPE powders[49] 
Journal Pre-proofs

\begin{tabular}{|l|l|l|}
\hline Property & \multicolumn{2}{|l|}{ Requirements in UHMWPE powder } \\
\hline Resin type & Type 1-2 & Type 3 \\
\hline Trade name & GUR 1020 and GUR 1050 & $1900 \mathrm{H}$ \\
\hline Ash, mg/kg (maximum) & 125 & 300 \\
\hline Titanium, ppm (maximum) & 40 & 150 \\
\hline Aluminium, ppm (maximum) & 20 & 100 \\
\hline Calcium, ppm (maximum) & 5 & 50 \\
\hline Chlorine, ppm (maximum) & 30 & 90 \\
\hline
\end{tabular}

The mechanical performance of UHMWPE is depending upon the average molecular weight, which is precisely derived from intrinsic viscosity quantification values[49]. The two methodologies available for finding average molecular weight based on Mark- Houwink equation is mathematically expressed using equation 1 and equation 2.

a) ASTM D4020-05:

$$
\mathrm{M} v=53700(\mathrm{IV}){ }^{1.37}
$$

\section{- equation 1}

Where, $\mathrm{M} v=$ average molecular weight, unit $=$ gram $/$ molecule

$$
\mathrm{IV}=\text { intrinsic viscosity, } \text { unit }=\text { deciliter per gram }
$$

b) Margolies equation (used apart from north American region)

$$
\mathrm{M} v=53700(\mathrm{IV}))^{1.49}
$$

\section{- equation 2}

Where, $\mathrm{M} v=$ average molecular weight, $\mathrm{unit}=$ gram $/$ molecule

$$
\mathrm{IV}=\text { intrinsic viscosity, } \mathrm{unit}=\text { deciliter per gram }
$$

The substitute methods for characterization of average molecular weight for UHMWPE material is sequential extraction[53] and gel permeation chromatography[54] (GPC), 
responsible for static friction performance and mechanical performance of UHMWPE[55]. The performance analysis of UHMWPE manufactured by various methodologies is summarized in table 3.

Table 3: Summary of mechanical and physical properties for medical grade UHMWPE[49]

\begin{tabular}{|c|c|c|c|}
\hline Quality of & Density of material & Ultimate tensile & Elongation (\%) to \\
UHMWPE material & $\left(\mathbf{K g} / \mathbf{m}^{\mathbf{3}}\right)$ & strength (MPa) & failure \\
\hline Extruded GUR 1020 & $935 \pm 1$ & $53.7 \pm 4.4$ & $452 \pm 19$ \\
\hline Molded GUR 1020 & $935 \pm 1$ & $51.1 \pm 7.7$ & $440 \pm 32$ \\
\hline Extruded GUR1050 & $931 \pm 1$ & $50.7 \pm 4.2$ & $395 \pm 23$ \\
\hline Molded GUR 1050 & $930 \pm 2$ & $46.8 \pm 6.4$ & 373 \\
\hline
\end{tabular}

\section{Methodologies for functionalization of UHMWPE:}

Among the various methodologies available for modification of UHMWPE in medical field, the methodologies are classified according to material used for functionalization process into two types, i.e. functionalization using various methodologies for surface treatment of UHMWPE or using various composite reinforcement materials for modifications in their bulk properties. The composite reinforced UHMWPE substrates are further classified according to it's end application in biomedical sector.

\subsection{Functionalization by surface treatment of virgin UHMWPE}

The functionalization of pure base material consisting of virgin medical grade UHMWPE is achieved by using electron beam treatment, cold atmospheric plasma in presence of air or filtered cathodic vacuum arc and plasma immersion using ion implantation. The investigation done by Irina Yu Grubova et al demonstrates the effect of electron beam 
treatment on UHMWPE, where the functionalization is carried out in presence of air to develop carbonyl and polar hydroxyl functional group. The functional group on the substrate surface has been originated by action of oxidizing agents, resulting in enhanced hydrophilicity and cell adhesion of UHMWPE polymer for medical applications. Prior the functionalization by electron beam, UHMWPE samples are thoroughly treated with deionized water in ultrasound bath for a duration of $10 \mathrm{~min}$. The samples were dried at a temperature of $70^{\circ}-80^{\circ} \mathrm{C}$ in a autoclave, followed by exposure of the material for surface modification using an accelerator by irradiation of electron beam on the sample surface at atmospheric pressure [56]. The observations were recorded for electron beam treatment from varying sample distance of $2 \mathrm{~cm}, 7 \mathrm{~cm}$ and $15 \mathrm{~cm}$ along with the varying treatment time of $5 \mathrm{~min}$, 20min, and $50 \mathrm{~min}$. The electron beam treatment on the UHMWPE surface resulted in concealing of the fibre surface and increment in surface roughness of polymer ( Figure 6), along with decrement in contact angle of water on the surface of polymer (after treatment for 21 days) when compared with untreated UHMWPE (contact angle close to 90)[57]. The polymer maintained it's adhesion, proliferation of fibroblast and spreading even after treated with an electron beam of $10.7 \mathrm{kGy}[43]$, exhibiting applications as a biomaterial used for bone implants[58]. The statistical analysis of ameliorated properties for the functionalized material is tabulated in table 4, demonstrating the comparison of average surface roughness and contact angle on the surface of substrate. 


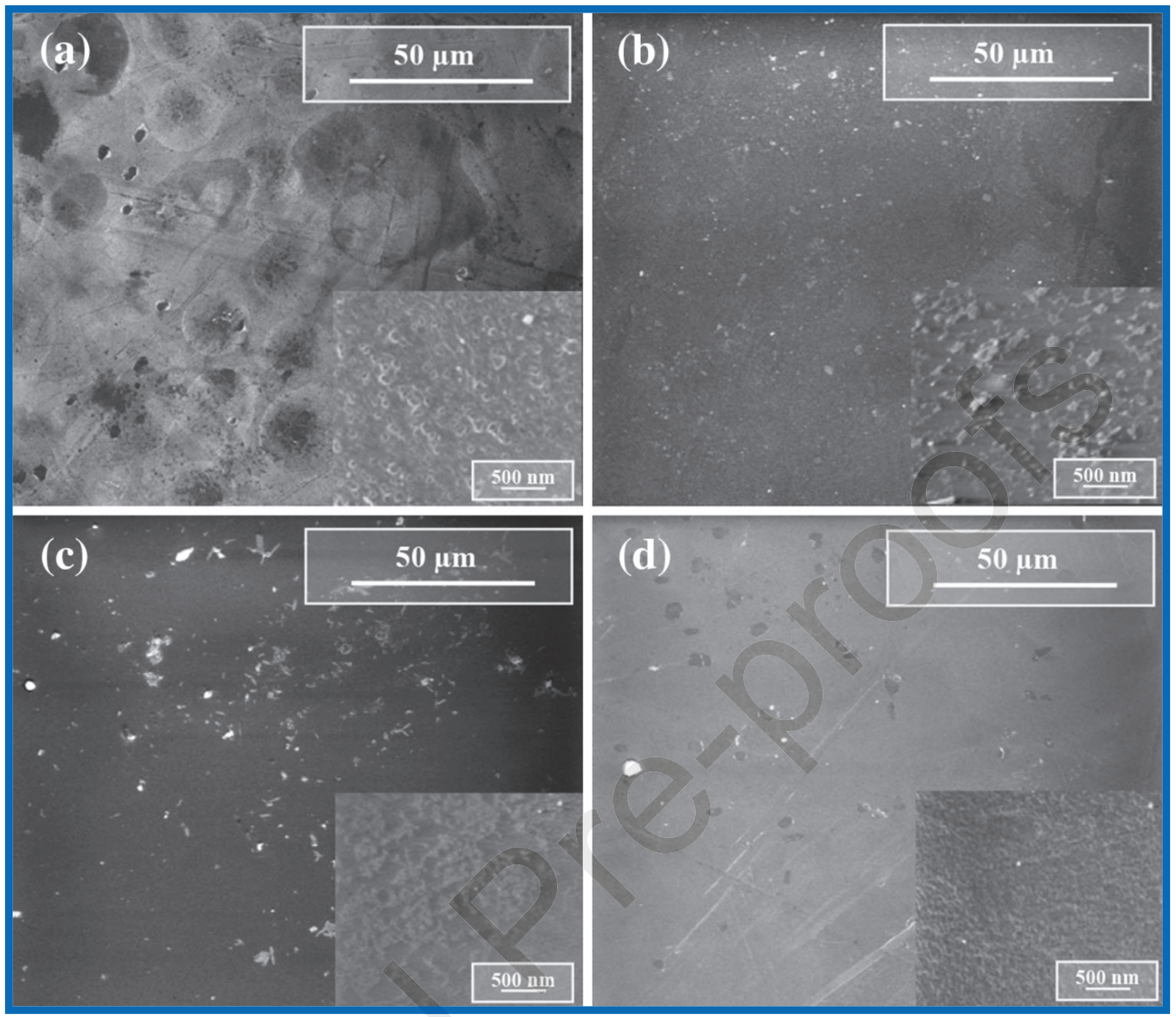

Figure 6: SEM images of electron beam treated UHMWPE, (a) untreated UHMWPE, (b)

UHMWPE2-50, (c) UHMWPE7-50, \& (d) UHMWPE15-50 [43].

Table 4: Analysis of surface roughness and contact angle after electron beam treatment [43]

\begin{tabular}{|c|c|c|}
\hline Sample & $\begin{array}{l}\text { Average Surface roughness } \\
\qquad(\mu \mathrm{m})\end{array}$ & Contact angle $\left({ }^{\circ}\right)$, (after 21 days) \\
\hline Untreated UHMWPE & $0.35 \pm 0.06$ & $96 \pm 3$ \\
\hline UHMWPE2-50 & $1.46 \pm 0.21$ & $28 \pm 2$ \\
\hline UHMWPE7- 50 & $0.83 \pm 0.10$ & $82 \pm 2$ \\
\hline UHMWPE15-50 & $0.56 \pm 0.01$ & $94 \pm 6$ \\
\hline
\end{tabular}


A similar study for functionalization of medical grade UHMWPE is derived from the detailed investigation carried out by Emily Collard Preedy et al, explaining the atmospheric cold plasma treatment on UHMWPE substrate in presence of air. In this method of functionalization, $\mathrm{He}$ (Helium) and $\mathrm{He} / \mathrm{O}_{2}$ cold gas plasma (CAP) has been used for surface modification of UHMWPE, imparting improved hydrophilicity and higher adhesion forces. The CAP technology is based on treatment of material using plasma, obtained by excitation of gas via applied energy source, leading to generation of plasma having adequate chemical species, charged particles, radicals and heat energy. CAP plasma can be developed by selective transfer of generator power to plasma electrons via high generation frequency[59]. The CAP device assembly consist of two electrodes, out of which one electrode is a capillary powered electrode trapped inside a quartz tube of $1.55 \mathrm{~mm}$ diameter and the other is downstream ring electrode enclosed outside the quartz surface, permitting axial separation ( Figure 7). Helium plasma were produced, permitting $5 \mathrm{slm}$ (standard litre per minute) of 99\% helium to pass through the capillary electrode[60], whereas Helium/oxygen plasmas were produced by mixing $10 \mathrm{sscm}$ (standard cubic centimetre per minute) of oxygen with helium gas prior to injection in CAP device. An alternating current of $8 \mathrm{kV}$ along with an excitation frequency of $20 \mathrm{KHz}$ was supplied to CAP device, which controls the breakdown of gas to generate an electrical discharge inside a quartz tube appearing as a plasma jet inside the quartz capillary. 


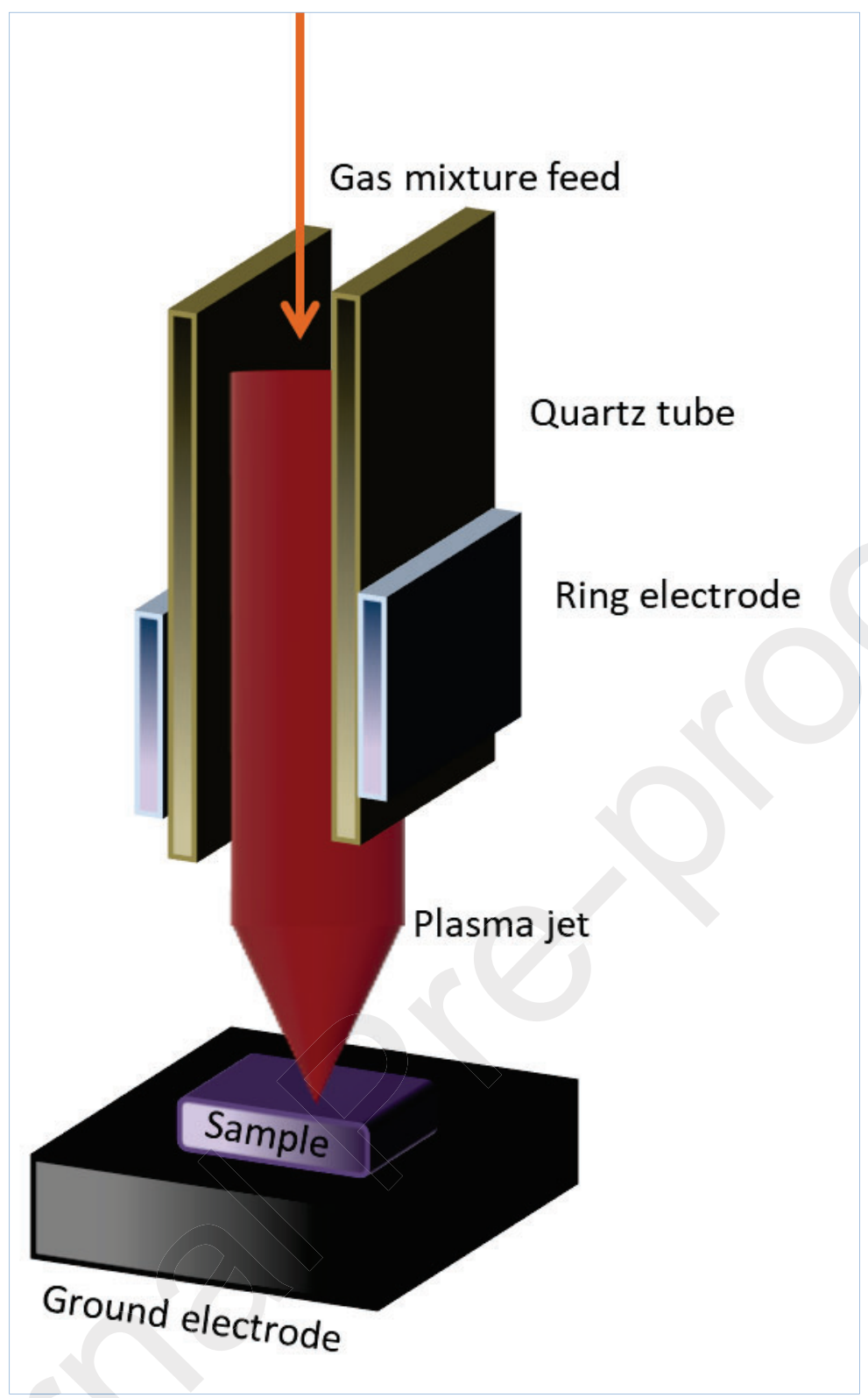

Figure 7: Cold atmospheric gas plasma treatment assembly

The CAP modified surface shows improved adhesion forces and good hydrophilicity as a result of decreased contact angle[44]. The ameliorated material exhibits a significant application in cell and protein adhesion on implant surface which helps in stimulating osseointegration process[61] ( table 5). The statistical data for contact angle and surface energy of functionalized UHMWPE surface using CAP technique is compared in table 5.

Table 5: Statistical analysis of CAP treated UHMWPE [44] 


\begin{tabular}{|c|c|c|}
\hline Sample & Contact angle for water $\left(^{\circ}\right)$ & Total surface energy $\left(\mathrm{mJ} / \mathrm{m}^{2}\right)$ \\
\hline Untreated UHMWPE & $70.4 \pm 1.5$ & 33.47 \\
\hline $\mathrm{He}$ & $46.1 \pm 2.5$ & 34.99 \\
\hline $\mathrm{He} / \mathrm{O}_{2}$ & $58.0 \pm 3.6$ & 36.77 \\
\hline
\end{tabular}

An innovative approach for functionalization of medical grade pure UHMWPE is demonstrated by the descriptive study of J. Y. Sze and B. K. Tay, explaining the modification of UHMWE using a filtered cathodic vacuum arc (FCVA) source and plasma immersion ion implantation with surface pulse biasing. FCVA is implemented to generate highly dense and ionized carbon ion plasma which strikes on a negatively pulse biased substrate, responsible for acceleration of carbon ions through plasma sheath to the substrate and ends up by being implanted on polymer, capable for making structural and chemical alterations in properties of polymer[62] ( Figure 8). This methodology is highly significant as it makes alterations in properties of UHMWPE without involving any other chemical element on surface of polymer. The functionalized material results in high purity and activity of substrate[63], along with excellent biocompatibility of UHMWPE material due to implantation of carbon atoms. The functionalization has been studied by varying implantation time on polymer surface, where comparison of results have shown that the nano-hardness of UHMWPE increases from 0.35 GPa (Untreated UHMWPE) to1.6 GPa when subjected to treatment of $10 \mathrm{kV}$ for $12 \mathrm{~min}$. Whereas increasing the contact time beyond this duration doesn't exhibit any significant alterations in properties of the polymer material[64]. The study of surface properties shows that there is also improvement in tribological properties of the polymer; the untreated UHMWPE has been recorded with wear rate of $67.5 \times 10^{-5} \mathrm{~mm}^{3} / \mathrm{Nm}$ whereas the wear rate is reduced up to $10 \times 10^{-5} \mathrm{~mm}^{3} / \mathrm{Nm}$ when the ions are implanted at $-5 \mathrm{kV}$ for duration of $5 \mathrm{~min}$, increment in contact time beyond this doesn't exhibited a significant decrease in 
wear rate[65]. Hence collectively the surface modification shows improved nano hardness, reduced wear rate and good biocompatibility[66] resulting in it's diverse application in biomaterials.

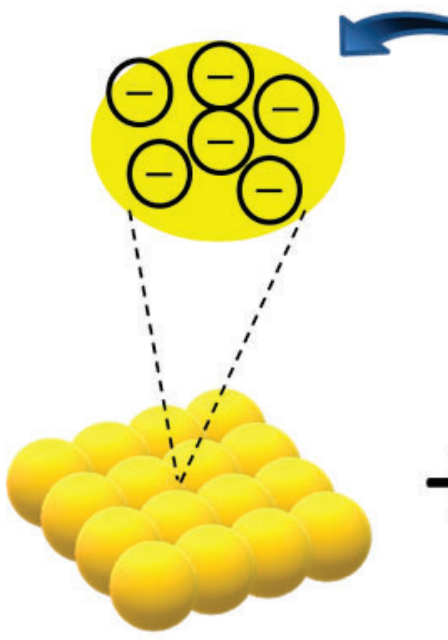

Negatively charged UHMWPE surface

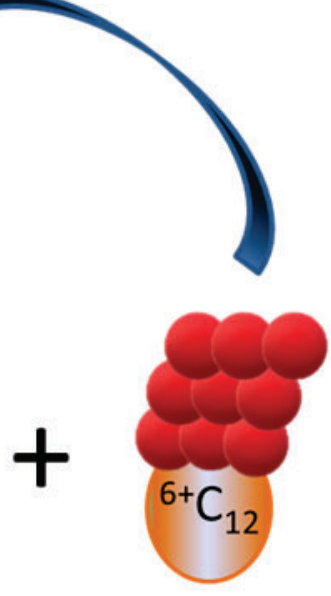

Carbon ion generated using FCVA

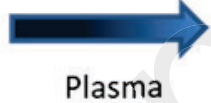
immersion
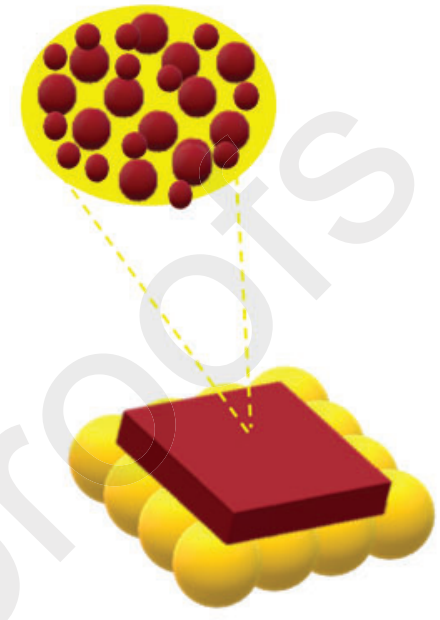

Carbon ion immersed substrate

Figure 8: Carbon ion immersion mechanism

\subsection{Functionalization by reinforcement of composites}

The improvements in bulk and surface properties of UHMWPE material can be achieved by utilization of various reinforcement composites blends or mixing of reinforcing agents with base matrix material of medical grade UHMWPE, exhibiting ameliorated properties of the substrate showcasing diverse applications as biomaterials. In this review the composites are classified based on end application of the functional material such as total hip arthroplasty, joint implants and bone tissue engineering.

\subsubsection{Total hip arthroplasty}

Among the various composites available for reinforcement of biomaterials, hydroxyapatite (HA) is widely used in various biomedical applications. An elaborative 
investigation done by Xiaomei Shi et al explains the wide consumption of hydroxyapatite with UHMWPE as reinforcing material, resulting in application of the developed substrate for hip prosthesis. The investigation emphasizes on various concentrations of hydroxyapatite blended with UHMWPE by using sol-gel process, the composites where hot molded, and the resultant agglomerates were molded within a temperature range of $145^{\circ} \mathrm{C}-153^{\circ} \mathrm{C}$. During the study, four concentrations of homogeneous solution consisting UHMWPE/HA composites were studied- 0 vol $\%, 13.3$ vol $\%, 23.5 \mathrm{vol} \%$ and $31.5 \mathrm{vol} \%$. The concentration of UHMWPE has been adjusted to $1 \mathrm{~g} / 100 \mathrm{ml}$ with respect to solvent.by following the process for MWCNT [67], developing a uniform dispersion of hydroxyapatite in paraffin oil solution by using ultrasonic and stirring for a duration of 12 hours. The mixture is heated to $145^{\circ} \mathrm{C}$ in presence of continuous stirring using a screw and isothermal conditions are maintained for duration of $30 \mathrm{~min}$. The extraction of UHMWPE/HA is done using hexane in an ice-water bath and resultant agglomerates are dried at a temperature of $60^{\circ} \mathrm{C}$ post extraction process. The agglomerates are compression molded $[19,68]$ at a narrow temperature range of $145^{\circ} \mathrm{C}-$ $153^{\circ} \mathrm{C}$ along with pressure adjusted to $3 \mathrm{MPa}$. 


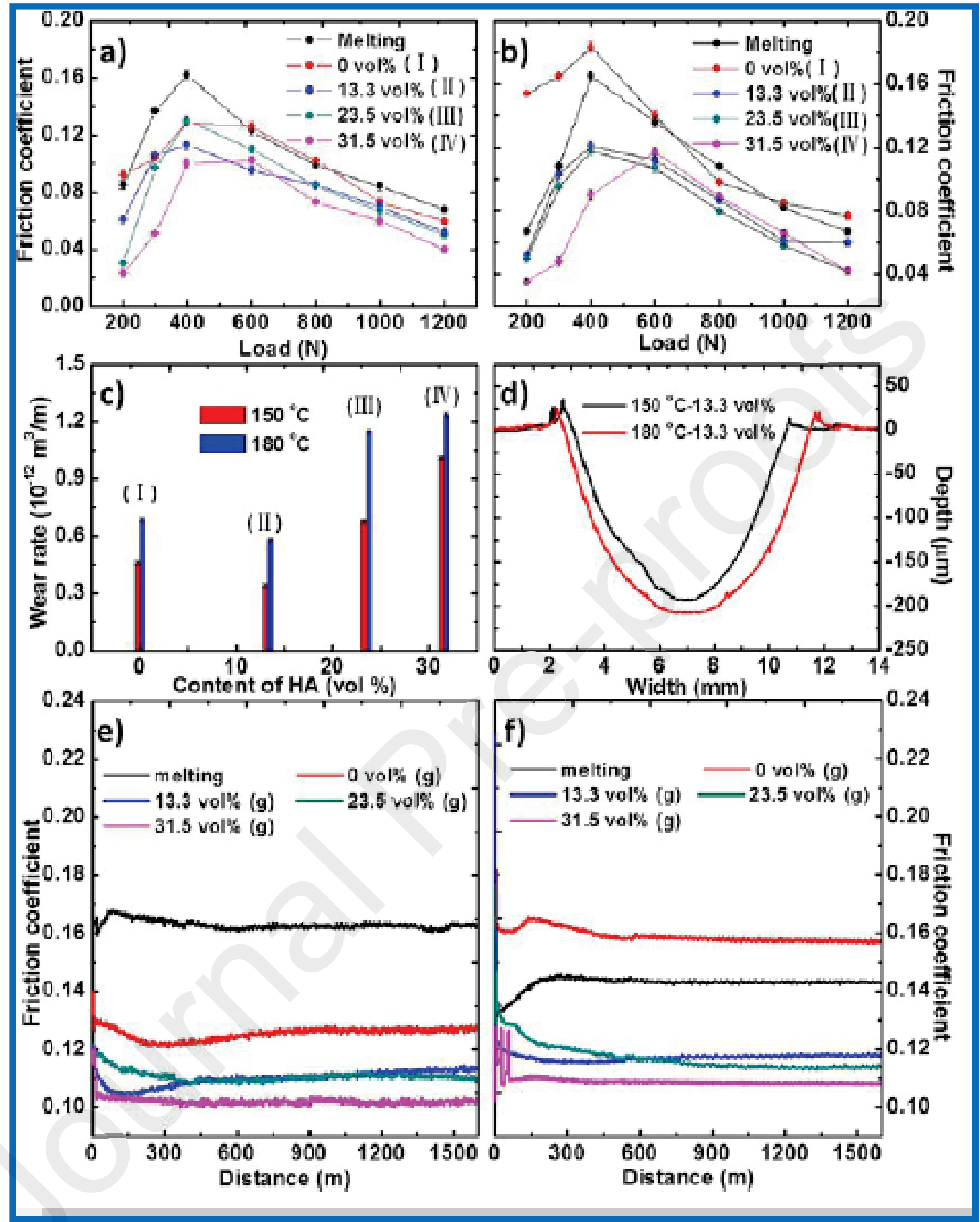

Figure 9: graphs (a) and (b) emphasize on coefficient of friction at $150^{\circ} \mathrm{C}$ and $180^{\circ} \mathrm{C}$ respectively, graph (c) shows wear rate at $150^{\circ} \mathrm{C}$ and $180^{\circ} \mathrm{C}$, (d) shows wearing measurement resulting in formation of shallow dent shapes, graph (e) along with graph (f) shows relation regarding coefficient of friction against distance travelled during wear test. [38] 
Figure 9 clearly demonstrates the increment in concentration of hydroxyapatite composite results in lowering the coefficient of friction of material, ensuring use of $31.5 \mathrm{vol} \%$ of HA to be consumed as an inner layer of the biomedical implant. On the contradictory part, it has been noticed that using higher concentrations of HA increases the wear rate of UHMEPE, whereas an alternative study explains the non-toxic nature of the wearing powder, but still controlling the wear debris of the HA reinforced UHMWPE need to be considered. SEM observations and EDS spectra observations explains the increment in amount of agglomerates present on surface of treated UHMWPE at a temperature of $150^{\circ} \mathrm{C}$, when compared with temperature of $180^{\circ} \mathrm{C}$ (Figure 9). The tribological properties of composites prepared by gelation process were superior compared to that of the kneading method. Due to the improvements in tribological properties and use of sol gel process for enhancement in processing resulted as the major reason for application of HA reinforced composite as a bearing material in total joint arthroplasty and artificial joints.[38]

A similar study investigated by Behraz Shirod Heidari et al demonstrated the utilization of nano-hydroxyapatite (nHA) as reinforcement composite for functionalization of UHMWPE to be used in biomedical application. The study is investigated for a reinforcement concentration of $10 \mathrm{wt} \%$ of nano-hydroxyapatite in UHMWPE/nHA composite, the complete homogeneous mixing of the two components is carried out using dry mechanical ball milling for the duration of 4 hours resulting in a UHMWPE/nHA composite having low coefficient of friction and wear resistance[69]. The samples produced are heated and subjected to hot pressing at elevated temperature of $200^{\circ} \mathrm{C}$ along with a pressure adjusted to $15 \mathrm{MPa}$ for duration of 2 hours. The part model was changed into autodesk moldflow[70] insight by injection molding process using a free from deformation methodology to avoid any shrinkage or fracture of the material during processing. The addition of nHA resulted in enhanced mechanical properties as well as biocompatibility of the material. The Statistical data 
explaining alterations in properties of UHMWPE is elaborated in table 6 . The UHMWPE/nHA hip liner is recommended over the UHMWPE liner due to it's improved biocompatibility and mechanical properties enabling it's application for hip prosthesis.

Table 6: Mechanical properties of UHMWPE/nHA composite[27].

\begin{tabular}{|l|l|l|l|l|l|}
\hline Sample & $\begin{array}{l}\text { nHA } \\
(\mathrm{wt} \%)\end{array}$ & $\begin{array}{l}\text { Density } \\
\left(\mathrm{gm} / \mathrm{cm}^{3}\right)\end{array}$ & $\begin{array}{l}\text { Elastic } \\
\text { modulus }(\mathrm{GPa})\end{array}$ & $\begin{array}{l}\text { Ultimate tensile } \\
\text { strength }(\mathrm{MPa})\end{array}$ & $\begin{array}{l}\text { Wear volume } \\
\left(\mathrm{mm}^{3}\right)\end{array}$ \\
\hline UHMWPE & 0 & 0.94 & 1.1 & 41.3 & 0.68 \\
\hline UHMWPE/nHA & 10 & 1.12 & 1.65 & 42.2 & 0.41 \\
\hline
\end{tabular}

The composite formation concerned with hydroxyapatite nanoparticle sometimes may lead to formation of nano-particle aggregates during the consolidation or molding process, resulting in non-uniform dispersion of the hydroxyapatite nanoparticles in composite material. The random and aggregated dispersion of the nanoparticles leads to crack formation in the composite, which further exhibits deprecated effects fatigue properties as well as reduced mechanical strength. The reinforcing nanoparticles has significantly smaller particle size when compared to polymeric materials, hence the nanoparticles are observed to be aggregated towards the gain boundary which results in non-uniform dispersion of nanoparticles further leading to variation in mechanical properties[71]. A study investigated by fang et al explains the methodologies to avoid the formation of nanoparticle aggregates during the manufacturing process, the study suggests implementation of the ball milling and swelling technique to develop nanoparticles of size $50 \mathrm{~nm}$ which were mixed with UHMWPE using injection molding or compression molding process[19]. The UHMWPE was swollen in medical grade paraffin oil to facilitate extrusion, where the paraffin oil was later extracted after fabrication using hexane[23]. 
An innovative approach for functionalization of UHMWPE was demonstrated by establishing reinforcement of composite as hydrophilic acrylic acid (AA) with the base matrix as UHMWPE material [72]. An elaborative study explained by Yaling Deng et al recorded the lowering in coefficient of friction and wear properties of biomedical implant, by achieving grafting of hydrophilic acrylic acid[73] on base UHMWPE powder using ultraviolet irradiation, followed by hot pressing of the modified powder. The grafting of material is carried out in inert atmosphere to eliminate the possibility of oxidation of grafting solution. The contact time of grafting solution determines the extent of grafting achieved on surface of material, where water is extracted from the grafted material for removal of homopolymers attached on the grafted surface. The grafting process leads to formation of branched polymers exhibiting significant surface properties such as wettability as well as mechanical properties[74]. The grafting of AA on UHMWPE powders has been achieved by photo induced graft polymerization ( Figure 10) resulting in ameliorated tribological properties as well as wettability, but the tensile strength of composite material is affected adversely causing decrement in strength of material when compared with the untreated UHMWPE. During the synthesis process, UHMWPE is sub merged into acetone solution containing 10 $\mathrm{mg} / \mathrm{mL}$ of benzophenone for duration of $10 \mathrm{~min}$, consequently drying of the powder is carried out in dark where benzophenone is prescribed as the initiator for self-initiated polymerization. Photo induced graft polymerization is carried out under high pressure 500W mercury lamp where the film filter is limited for passage of ultraviolet rays. The powder is further dried to eliminate the ethanol content, the modified material is subjected to compression molding in a vacuum hot forming furnace at a temperature of $150^{\circ} \mathrm{C}$ for duration of $2.5 \mathrm{hrs}$. A pressure condition of $7.5 \mathrm{MPa}$ is maintained for $30 \mathrm{~min}$ to eliminate thermal deformation of material during cooling. 


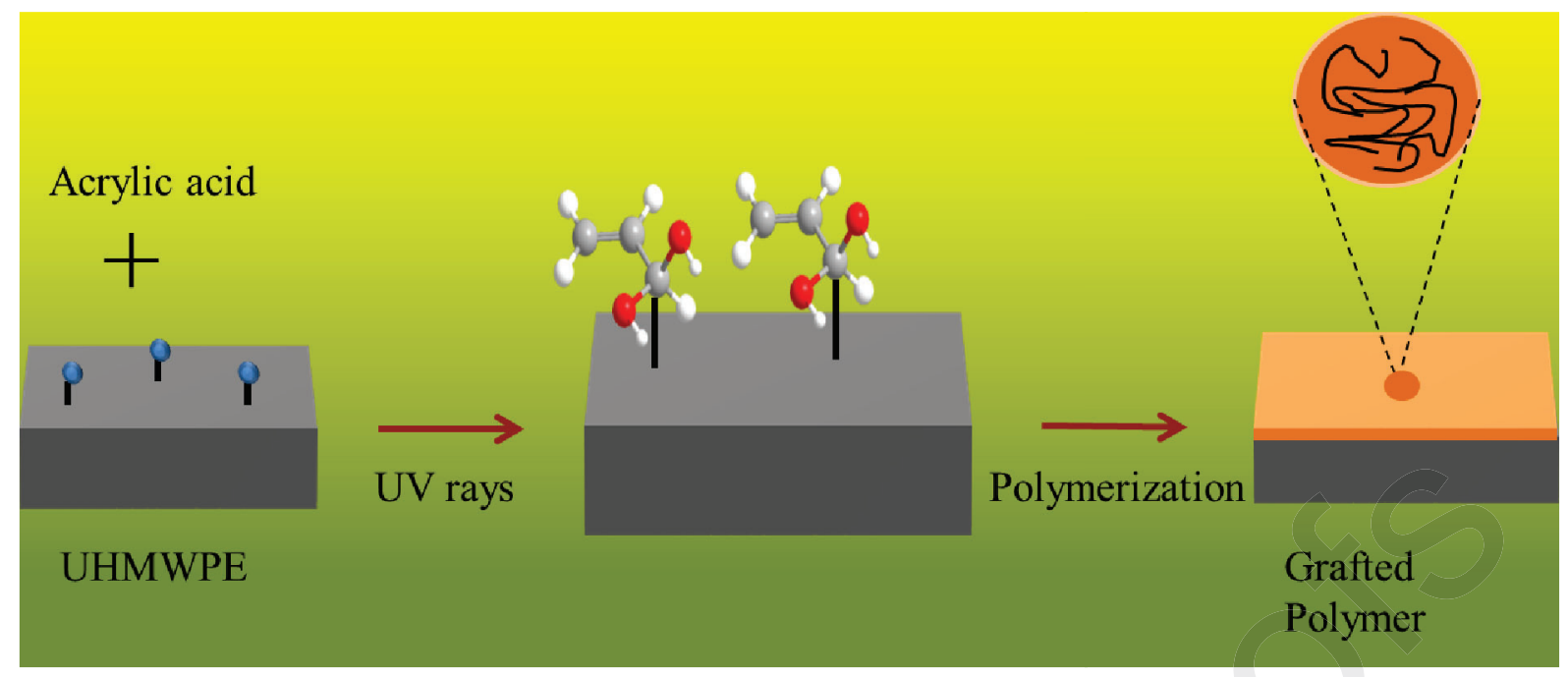

Figure 10: Acrylic acid grafting process sequence

The functionalized UHMWPE with AA grafting results in improved wettability at a grafting ratio of $5.5 \%$,where the contact angle of water has been significantly reduced from $83^{\circ}$ (Untreated UHMWPE) to $35^{\circ}$ (AA treated UHMWPE sample)[75]. The functionalized material shows enhanced tribological properties, the testing of the material is carried out in saline, calf serum and distilled water conditions, where the coefficient of friction is recorded as $(0.222,0.155$, and 0.225$)$ compared to that of untreated UHMWPE $(0.228,0.180$ and 0.227 ) respectively. The wear rate of modified UHMWPE with a graft ratio of $2.16 \%, 3.5 \%$ and $5.5 \%$ decreases by $54 \%, 75 \%$ and $25 \%$ respectively in presence of calf serum evaluated using international ISO 14242-1[76]. The limitation of AA grafting on UHMWPE is observed as decrement in tensile strength, where the tensile strength reduces from $55.05 \mathrm{MPa}$ (Untreated UHMWPE) to $46.61 \mathrm{MPa}$ (AA treated UHMWPE). The final result concludes that the modified UHMWPE with a graft ratio of 3.5\% shows lowest wear rate, it is usually recommended for it's use in artificial hip joints to avoid osteolysis caused due to wear particles of PE[75].

M. P. Gispert et al discovered an innovative way for functionalization of UHMWPE ; the study explained about chlorine implantation on TiN coatings resulting in improved 
tribological behaviour of a prosthetic pair. During the manufacturing process, stainless steel counterpart is coated with TiN coating using deposition of PVD arc evaporation (Figure 11) by METAPLAS coating machine at elevated temperature of $300^{\circ} \mathrm{C}$. The TiN coated substrates are implanted with chlorine atoms at room temperature using fluence of $1 \times 10^{17} \mathrm{~cm}^{-}$ ${ }^{2}$ along with energy of $150 \mathrm{keV}$. The chlorine implanted substrates are further treated in an ultrasonic bath containing dilute Extran solution for duration of $10 \mathrm{~min}$ followed by it's treatment with deionised water for $10 \mathrm{~min}$, the drying of substrates for overnight is achieved at room temperature inside a vacuum oven[77]. The linear increment in friction coefficient of the $\mathrm{Cl}$ implanted substrate with increase of distance, whereas when it is compared with the argon implanted substrates, the $\mathrm{Cl}$ implanted substrate shows significantly lower values for coefficient of friction. It leads to a conclusion that $\mathrm{Cl}$ implanted substratesexhibited better tribological properties compared to that of the other substrates[78]. The surface energy and wettability measurements explains the lower contact angles of $\mathrm{Cl}$ implanted substrate when compared with other substrates, exhibiting improved hydrophilicity of the material along with reduced surface free energy from $47 \pm 2$ (TiN coated) to $43 \pm 2$ (TiN-Cl implanted coating)[77]. The improved tribological and wettability properties of $\mathrm{Cl}$ implanted substrate enable it's application in hip prosthesis to counter against the rheumatic diseases such as osteoarthritis and rheumatoid. 


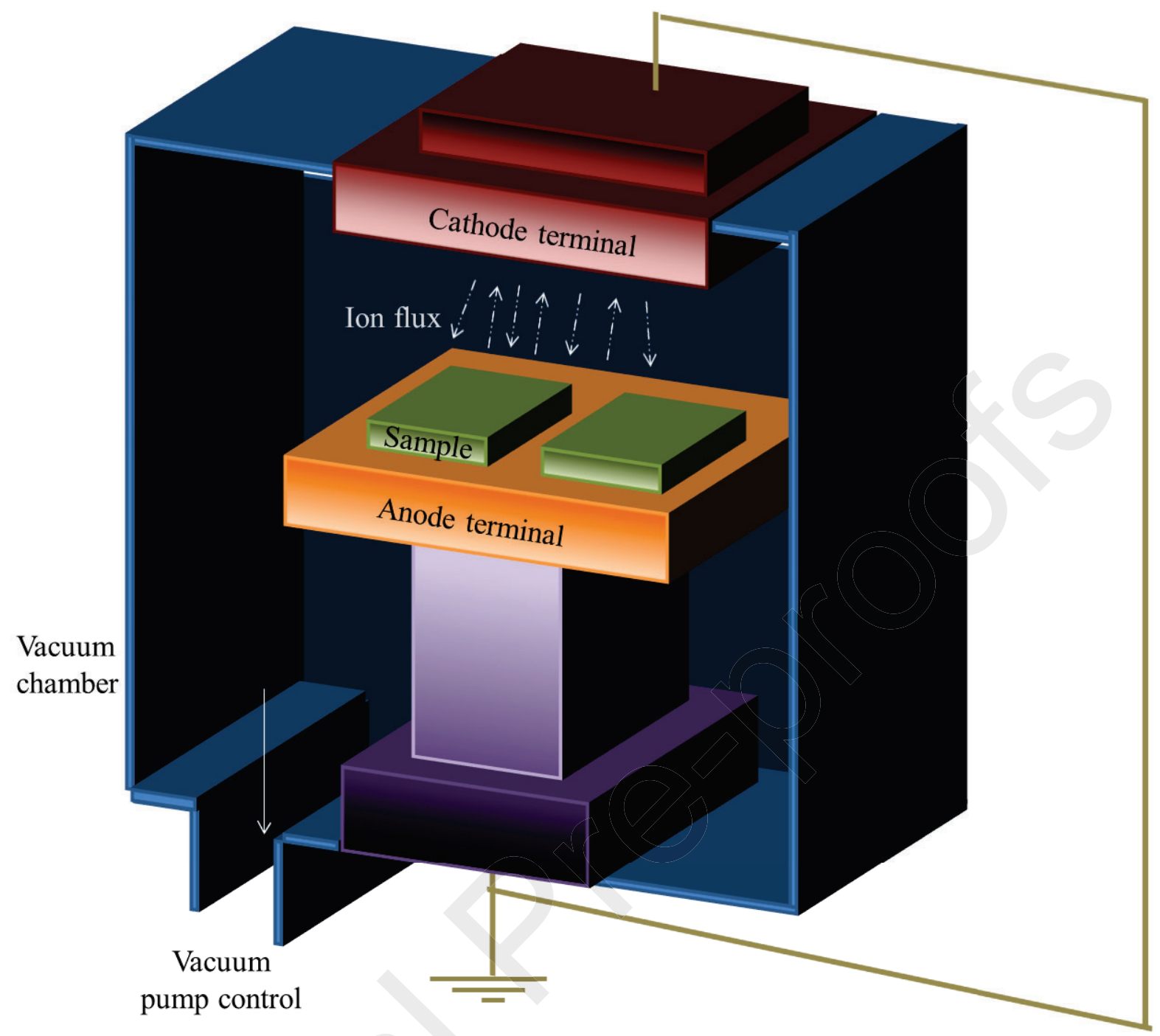

Figure 11: $\mathrm{PVD}$ technique for $\mathrm{Cl}$ ion implantation

The descriptive study done by V. P. Poliakov et al demonstrated the use of diamond like carbon films as reinforcement material of UHMWPE having application in artificial hip prosthesis[79,80].During the manufacturing process, UHMWPE substrate was deposited with the DLC film by physical vapour deposition (PVD) technique[81] (Figure 11) consisting of pulsed arc plasma. The substrates were cleaned with carbon tetrachloride, followed by drying before vacuum treatment. The substrate is striked with argon and titanium ions inside the vacuum chamber, resulting in deposition of small particles of titanium implantation on the upper layer of substrate. The substrate is further deposited with fine Ti and DLC coating with a uniform film thickness of $250 \mathrm{~nm}$ at temperature range of $25^{\circ} \mathrm{C}-30^{\circ} \mathrm{C}$ and uniform speed 
of $20 \mathrm{~nm} / \mathrm{min}$. The characterization of mechanical properties provided by material is tested by nanoindentation (nanoindenter XP MTS system)[82], along with adhesion test and coefficient of friction measurement. According to the recorded readings, it has been noticed that DLC coated UHMWPE exhibited better nano-hardness and elastic modulus. The hardness of substrate increases from 0.01 GPa (Untreated UHMWPE hardness) to $20 \mathrm{GPa}$ (DLC coated UHMWPE) as well as the elastic modulus of DLC coated sample as $100 \mathrm{GPa}$. The adhesion test is carried out by scratching to the substrate surface, whereas readings recorded shows that the surface was completely worn out after scratching with a force of $50-55 \mathrm{~N}$. The coefficient of friction for DLC coated UHMWPE shows marginal decrement in their readings, as coefficient of friction decreases form 0.16 (initial/untreated UHMWPE) to 0.12 (steady state/DLC coated)[28]. According to the recorded data, it can be concluded that DLC coated films on UHMWPE shows improved hardness, elastic modulus and lowered coefficient of friction properties required for it's use in prosthetic pairs.

\subsubsection{Joint replacements}

There has been bunch of materials available that can be used as a reinforcement composite for altering the properties of UHMWPE, utilized for it's application in joint replacements. A wide research has been focused on ameliorating the lifetime of joint implants used in human body, as the biomedical implant leads to wear debris when subjected with actions of human body serum fluids causing release of wear particles in human body.

Among the various researchers, Jun Fu et al demonstrated the use of gallic acid (GA) and dodecyl gallate (DG) as a composite for imparting oxidation stability, wear resistance and improved mechanical properties of highly cross-linked UHMWPE. Antioxidant plays a vital role in stabilization of material during irradiation such that it doesn't require post irradiation treatment; hence vitamin $\mathrm{E}$ is added as antioxidant providing irradiation stability to the material. Manufacturing of composite is achieved by using a mixture of gallic acid, 
dodecyl gallate and vitamin E, blended together with UHMWPE (Figure 12)having concentration of $0.05 \mathrm{wt} \%$ and $0.1 \mathrm{wt} \%$ at consolidation temperature of $190^{\circ} \mathrm{C}$. The blending process is highly significant for controlling the formation of nanoparticle agglomerates during the molding process, a similar study done by Latifa Melk and Nazanin Emami explained the formation of fine dispersion of carbon nanotubes and graphene based UHMWPE/Vitamin E matrix by utilization of tip ultrasonicator[83]. The vacuum packing of consolidated blocks is carried out and exposed to an irradiation of $10 \mathrm{MeV}$ electron beam at $25 \mathrm{kGy}$ per pass with the varying dosage increasing up to $50 \mathrm{kGy}, 100 \mathrm{kGy}, 150 \mathrm{kGy}$ at room temperature. The precaution was taken that temperature shouldn't elevate beyond $50^{\circ} \mathrm{C}$ even after the action of irradiation.

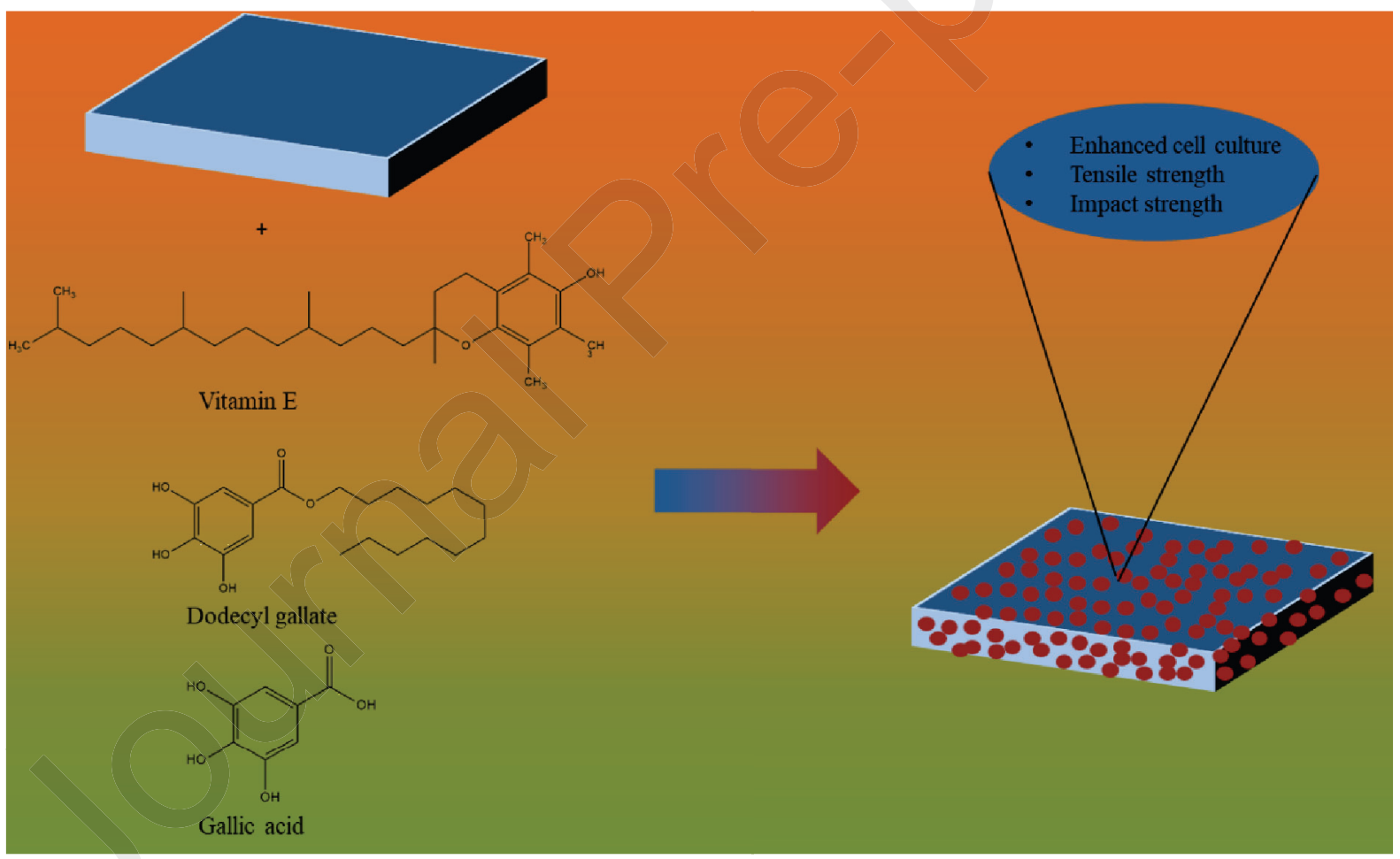

Figure 12: Schematic representation of UHMWPE/GA/DG/VE composite

The irradiation to Antioxidant/UHMWPE for long duration of time at elevated temperature for ageing, determines the anti-oxidation potential of vitamin E and polyphenols. The tensile strength properties for various concentrations of polyphenols for aged sample are tabulated in table 7. The composite of GA, DG and vitamin E doesn't causes a marginal decrement in 
crosslinking density of UHMWPE, even at high concentrations of antioxidants irradiated at high dosage of rays.

Table 7: Tensile strength and impact strength properties of VE, DG and GA reinforced UHMWPE[84].

\begin{tabular}{|c|c|c|c|c|c|c|c|}
\hline Properties & $\begin{array}{l}\text { Dose } \\
\text { (kGy) }\end{array}$ & $\begin{array}{l}0.05 \% \\
\text { VE }\end{array}$ & $0.1 \%$ VE & $\begin{array}{l}0.05 \% \\
\text { DG }\end{array}$ & $0.1 \%$ DG & $\begin{array}{l}0.05 \% \\
\text { GA }\end{array}$ & $\begin{array}{l}0.1 \% \\
\text { GA }\end{array}$ \\
\hline \multirow[t]{3}{*}{$\begin{array}{l}\text { UTS } \\
(\mathrm{MPa})\end{array}$} & 0 & $\begin{array}{l}48.3 \pm \\
4.6\end{array}$ & $63.5 \pm 4.2$ & $61.3 \pm 10$ & $65.8 \pm 5.5$ & $56.2 \pm 4.1$ & $\begin{array}{l}56.7 \pm \\
2.5\end{array}$ \\
\hline & 50 & $\begin{array}{l}50.4 \pm \\
6.5\end{array}$ & $64.1 \pm 2.8$ & $58.9 \pm 6.8$ & $60.8 \pm 3.0$ & $53.0 \pm 2.6$ & $\begin{array}{l}50.5 \pm \\
1.6\end{array}$ \\
\hline & 100 & NA & $55.2 \pm 4.7$ & $50.4 \pm 1.4$ & $54.8 \pm 5.4$ & $44.7 \pm 3.3$ & $\begin{array}{l}47.6 \pm \\
4.4\end{array}$ \\
\hline \multirow{3}{*}{$\begin{array}{l}\text { Impact } \\
\text { strength } \\
\left(\mathrm{kJ} \mathrm{m}^{-2}\right)\end{array}$} & 0 & $134 \pm 8$ & $126 \pm 11$ & $123 \pm 12$ & $118 \pm 18$ & $113 \pm 9$ & $131 \pm 17$ \\
\hline & 50 & $90 \pm 1$ & $101 \pm 7$ & $94 \pm 3$ & $104 \pm 5$ & $101 \pm 9$ & $99 \pm 8$ \\
\hline & 100 & $10 \pm 1$ & $61 \pm 4$ & $53 \pm 5$ & $82 \pm 1$ & $61 \pm 0.1$ & $59 \pm 7$ \\
\hline
\end{tabular}

The melting point of the AO/UHMWPE blend is unaffected due to alterations in the properties of concentrations in composites, whereas crystallinity increases with increment in GA and DG contents of the composite material compared to that of minimal decrement in crystallinity with increase of vitamin E content (Table 8). The effect on composite blend when subjected to dosage of $100 \mathrm{kGy}$ has been recorded, the statistical data comprising of the melting point and crystallinity is represented in table 8 . The improved tensile properties along with the oxidation stability enable application of functionalized material in joint replacements to avoid the wear and loosening of the implants by osteolysis. 
Table 8: melting point and oxidation stability of vitamin E, GA and DG reinforced UHMWPE[84].

\begin{tabular}{|c|c|c|c|c|c|}
\hline \multirow[t]{2}{*}{ Sample } & \multirow[t]{2}{*}{ Dose } & \multicolumn{2}{|c|}{ Melting point $\left({ }^{\circ} \mathrm{C}\right)$} & \multicolumn{2}{|c|}{ Crystallinity (\%) } \\
\hline & & 0.05 wt\% & $0.1 \mathrm{wt} \%$ & 0.05 wt\% & $0.1 \mathrm{wt} \%$ \\
\hline \multirow{3}{*}{$\begin{array}{l}\text { Untreated } \\
\text { UHMWPE }\end{array}$} & 0 & 136 & - & 50.3 & - \\
\hline & 50 & 139.1 & - & 58.9 & \\
\hline & 100 & 141.7 & - & 57.7 & - \\
\hline \multirow[t]{3}{*}{ Vitamin E } & 0 & 136.8 & 136.5 & 60.3 & 58.5 \\
\hline & 50 & 140.3 & 139.5 & 58.1 & 56.4 \\
\hline & 100 & 141.7 & 141.9 & $50 . \overline{3}$ & 51.4 \\
\hline \multirow[t]{3}{*}{ Gallic acid } & 0 & 137 & 136.6 & 56.5 & 60.5 \\
\hline & 50 & 138.8 & 137.8 & 58.9 & 58.8 \\
\hline & 100 & 141.3 & 141.2 & 63.5 & 58.9 \\
\hline \multirow{3}{*}{$\begin{array}{l}\text { Dodecyl } \\
\text { gallate }\end{array}$} & 0 & 136.9 & 136 & 57.5 & 61.7 \\
\hline & 50 & 140.2 & 139.3 & 61.8 & 57.0 \\
\hline & 100 & 140.3 & 140.4 & 60.0 & 57.5 \\
\hline
\end{tabular}

A similar approach to enhance the oxidative resistance of the material is elaborately explained by S.M. Kurtz et al, the study elaborated utilization of vitamin E composite with UHMWPE to reduce oxidative degradation of material. The medical grade UHMWPE samples were blended with varying concentrations of vitamin E (0 ppm, $125 \mathrm{ppm}, 250 \mathrm{ppm}$, $375 \mathrm{ppm}, 500 \mathrm{ppm})$, implementing the standard compression molding cycle by following regulations of ISO 11542-2. Tensile strength properties measured using standard ASTM techniques reported no significant results with increment in vitamin E concentration, whereas a decrement in tensile strength was observed with ageing (about 4 weeks) of functionalized 
material. According to FTIR study, the addition of vitamin E results in improved oxidative stability of the material, highly concentrated composite material (375 ppm, $500 \mathrm{ppm})$ acts as consistent oxidative stable material even after subjected to ageing for duration of four weeks. The study explained satisfactory results for oxidation stability of functionalized material and enables it's application in joint replacements as an important composite material. An analogous approach for modification in properties of UHMWPE using vitamin $\mathrm{E}$ as reinforcement is demonstrated by Filippo Reno and Mario Cannas et al, according to their observations wear resistance as well as oxidative resistance in medical implant can be improved using reinforcement of vitamin $\mathrm{E}$ acting as an antioxidant, lipophilic, biocompatible and inflammatory material. The addition of $0.3 \mathrm{wt} \%$ vitamin E reflects the needful alterations by preventing oxidation and inflammation along with a long term fatigue resistive performance[85] and improved bioactivity[86]. When the virgin UHMWPE and UHMWPE/Vitamin E composite are treated with body plasma at $37^{\circ} \mathrm{C}$ for duration of 1 hour, the two samples absorbed comparable quantity of plasma proteins (UHMWPE $=2.1 \pm 1.0$ $\mu \mathrm{g} / \mathrm{cm}^{2}, \mathrm{UHMWPE} /$ Vitamin $\left.\mathrm{E}=1.6 \pm 0.2 \mu \mathrm{g} / \mathrm{cm}^{2}\right)$. A similar approach of using Vitamin $\mathrm{E}$ as reinforcement of UHMWPE was studied by P. Bracco et al, demonstrating the action of Vitamin $\mathrm{E}$ as an oxidation stabilizer of UHMWPE at concentration of $0.05 \mathrm{w} / \mathrm{w} \%, 0.1 \mathrm{w} / \mathrm{w} \%$, $0.5 \mathrm{w} / \mathrm{w} \%$. It was fused together by process of compression moulding carried out at standard high temperature and high pressure used for manufacturing of medical grade UHMWPE[48]. The FTIR spectroscopy of samples irradiated by gamma ray at various doses $(0 \mathrm{kGy}, 30 \mathrm{kGy}$, $100 \mathrm{kGy}$ ) recorded a decrement in absorption band having maxima at $960 \mathrm{~cm}^{-1}$, whereas increasing the radiation dose resulting in shift of absorption maxima to $965 \mathrm{~cm}^{-1}$. After the irradiation with gamma rays, a slight presence of ketonic groups on reinforced substrate is observed; whereas the concentration of ketonic groups was increased with ageing of material. Depending upon the obtained results, a conclusion was noted that addition of vitamin $\mathrm{E}$ as 
reinforcement shows high stabilisation to sterilised or cross-linked dose providing improved oxidative resistance even compared to irradiated UHMWPE.

An investigation done by Nitturi Naresh Kumar et al explained the effect of argon plasma treatment on multi walled carbon nanotubes (MWCNTs) reinforced UHMWPE; his study interprets the improved mechanical and tribological properties along with hydrophobicity of reinforced material. The chemically treated UHMWPE is dispersed homogeneously in a polymer matrix which is further treated with nitric acid and sulphuric acid in a ratio of $1: 3$ at boiling temperature of $140^{\circ} \mathrm{C}$ for duration of $140 \mathrm{~min}$, followed by drying of samples at $100^{\circ} \mathrm{C}$. The composite is physically blended with UHMWPE at various concentrations of $0.5 \mathrm{wt} \%, 1 \mathrm{wt} \%, 1.5 \mathrm{wt} \%$ and $2 \mathrm{wt} \%$, the compression molding of nanocomposite (manufactured using ball milling machine) is achieved within a temperature range of $220^{\circ} \mathrm{C}-230^{\circ} \mathrm{C}$ along with a pressure adjusted at $10 \mathrm{MPa}$ for duration of $60 \mathrm{~min}$, and subsequently the substrate is subjected to cooling at room temperature. The nano-composite material sheets are subjected to cleaning using acetone and ethanol for $5 \mathrm{~min}$, and successive drying in vacuum chamber at $40^{\circ} \mathrm{C}$ for 24 hours is necessary. The argon plasma generation is achieved by passage of argon gas through a dielectric barrier discharge (DBD) chamber (Figure 13) maintained at 18.5 mbar at an alternating current of frequency $50 \mathrm{~Hz}$ applied across the electrodes of ballast resistor $(4 \mathrm{M} \Omega)$ with a P-P voltage of $15 \mathrm{kV}$. The nanocomposite material is deposited for varying contact time leading to various concentrations of UHMWPE/MWCNTs material. 


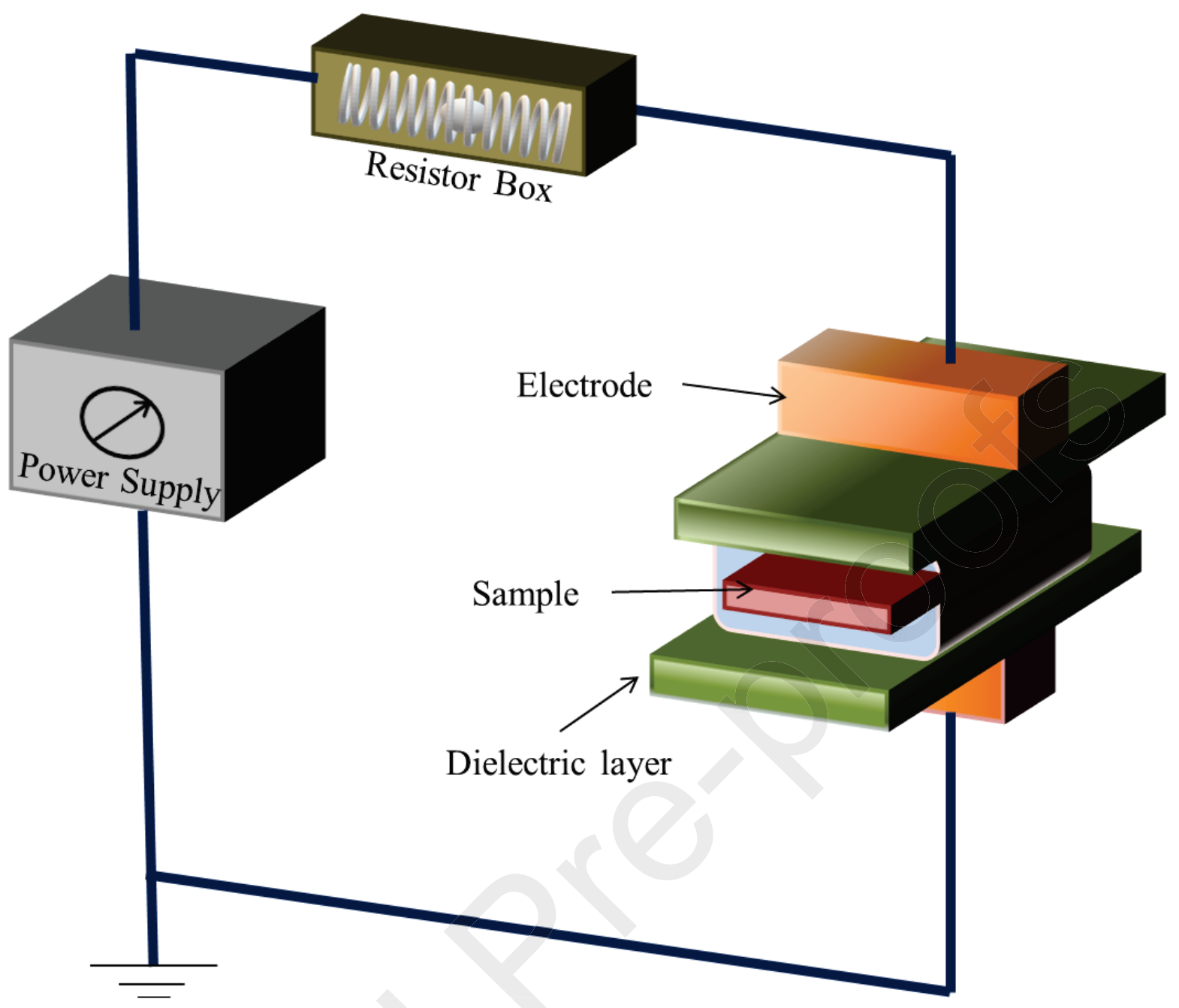

Figure 13: Schematic diagram of DBD

The functionalization of UHMWPE/MWCNTs material with argon plasma treatment results in improved hydrophilicity, where the contact angle of functionalized material significantly reduces from $78.1^{\circ}$ (Untreated UHMWPE/MWCNTs) to $37.1^{\circ}$ (plasma treated) for concentration $2 \mathrm{wt} \%$ MWCNTs when exposed to argon plasma for duration of $60 \mathrm{~min}[87]$. It has been experimentally noticed that increase in concentration of MWCNTs and contact time of argon plasma results in decreased contact angle of material, ensuring the functionalized material becoming more hydrophilic exhibiting better tribological properties[88]. The similar trend has been observed for wear volume of UHMWPE/MWCNTs material, in dry conditions, wear volume for 2\% MWCNTs reinforced UHMWPE material reduces from 0.4 $\mathrm{mm}^{3}$ (Untreated) to $0.21 \mathrm{~mm}^{3}$ (argon plasma treated for $60 \mathrm{~min}$ ) which further reduces to 
$0.086 \mathrm{~mm}^{3}$ in presence of $\mathrm{N}$ - saline lubricated condition. In presence of the same treatment parameters the sustrate corresponds to $62 \%$ reduction in wear volume compared to performance in dry conditions[89]. It has been recorded that increase in concentration of MWCNTs results in increased hardness of the material, which can be concluded as a reason for improved crystallinity of the material[90]. The functionalized UHMWPE/MWCNTs treated with argon plasma treatment proclaim improved wettability, hardness, wear resistance and coefficient of friction which has numerous applications in joint implants.

A study investigated by J.A. Puertolas and S.M. Kurtz explained segregated structure of CNT reinforced UHMWPE material regardless of the manufacturing process for developing a functionalized material. The segregated structure leads to formation of structural defects in microstructure of UHMWPE, influencing mechanical properties of the material. Lack of efficacy associated with aggregation of carbon nanotubes is due to the partial dispersion of carbon nanotubes along with random distribution of nanoparticles in the matrix. The reduced graphene oxide has been utilized as a possible measure to reduce the aggregation of carbon nanotubes prior to hot processing of composite material at elevated temperature of $200^{\circ} \mathrm{C}$ [91].

The alternative approach to improve wear resistance of UHMWPE was explained by M Bianchi et al, focusing on coating of metallic counterpart by zirconium dioxide thin filmwhich eventually results in lowered wear of UHMWPE implants. The thin film of zirconium dioxide is deposited by pulsed plasma deposition; the substrates were priorly subjected to cleaning using acetone and isopropanol, and then dried in a nitrogen flux. According to experimental readings, it has been recorded that the contact angle of substrate decreases with increase in applied pressure, the serum conditions $\left(62^{\circ} \pm 2^{\circ}\right)$ shows slightly lower contact angles compares to that of saline condition $\left(63^{\circ} \pm 3^{\circ}\right)$ [92]. Wear rate of zirconium coated substrate is governed by the optimum pressure conditions, the substrate 
applied with a pressure of $6 \times 10^{-3}$ mbar shows lowest wear rate (in dry conditions $6.3 \pm 0.5$ $\left.\mathrm{mm}^{3} / \mathrm{Nm}\right)$, whereas it shows marginal decrement in serum conditions $(4.5 \pm 0.4$ $\left.\mathrm{mm}^{3} / \mathrm{Nm}\right)[93,94]$. The biological test of substrate shows absence of cytotoxicity and overall the zirconia film coated substrate exhibited improved biocompatibility of material. The functionalized material having improved tribological properties and better biocompatibility has numerous applications in total joint implants majorly focused on knee and shoulder replacement. A similar study of zirconia coatings on titanium surface has been conducted by M. Berni et al, his recordings focuses on study of $2 \mu \mathrm{m}$ thick yttria stabilized zirconia (YSZ) coatings on the metallic surface using pulsed plasma deposition (PPD). The YSZ coating is deposited by ablating of $3 \mathrm{~mol} \%$ zirconium dioxide by cold isotactic pressing at a pressure of $30 \mathrm{MPa}$ for duration of 60 seconds, followed by sintering at $1500^{\circ} \mathrm{C}$ for duration of 1 hour. The deposition of YSZ coating is carried out using PPD technique at high energy $\left(10 \mathrm{~J} \times \mathrm{cm}^{-}\right.$ $\left.{ }^{2}\right)$, high density of electrons $\left(108 \mathrm{~W} \times \mathrm{cm}^{-2}\right)$ and fast pulse $(100 \mathrm{~ns})$. The YSZ coated substrate shows improved hardness $(\mathrm{H})$ and elastic modulus (E) when tested by nanoindentation test, which statistically increases from $\mathrm{H}=5.48 \pm 0.411 \mathrm{GPa} \& \mathrm{E}=133 \pm 10 \mathrm{GPa}$ (untreated substrate) to $\mathrm{H}=11.11 \pm 1.1 \mathrm{GPa} \& \mathrm{E}=195.8 \pm 27.8 \mathrm{GPa}$ (YSZ coated substrate). The samples were exposed to vigorous testing for determining wear rate at a distance of $10 \mathrm{~km}$, whereas the data recorded after testing implies the lowered wear rate of coated sample from $1.29 \times 10^{-5} \pm 3.55 \times 10^{-7} \mathrm{~mm} 3 /(\mathrm{Nm})$ (untreated sample) to $1.06 \times 10^{-5} \pm 4.71 \times 10^{-7}$ mm3/(Nm) (YSZ coated sample)[95,96]'. The YSZ coated samples shows marginal decrement in coefficient of friction of material, it reduces from $0.22 \pm 0.01$ to $0.13 \pm 0.02$ when subjected to testing at a distance of $10 \mathrm{~km}$, whereas a general observation was recorded that coefficient of friction varies depending on testing conditions such as applied load and sliding speed[97]. Hence the investigation of M. Berni et al can be concluded the YSZ coated 
metallic substrate using PPD technique, as a counter part of UHMWPE material results in enhanced tribological properties having significant application in total joint arthroplasty.

A concept of self-reinforced UHMWPE for medical application was demonstrated by Yan-Fei Huang et al, according to their studies, they had developed self-reinforced UHMWPE material by addition of $9.8 \mathrm{wt} \%$ melt processable ultra low molecular weight polyethylene (ULMWPE) which acts as flow accelerator. The material is manufactured using $2 \%$ UHMWPE blended with 98\% ULMWPE in presence of xylene at temperature of $140^{\circ} \mathrm{C}$, to obtain a molecular level uniform dispersion capable of forming highly entangles shishkebabs structure[98,99]. The polymer synthesized is then subjected to precipitation in cold alcohol in presence of continuous stirring, extracted solid is then filtered out and dried in presence of vacuum at $60^{\circ} \mathrm{C}$ for about 2 weeks. The complete removal of solvent from the material such that no weight loss should occur on heating of the dried material up to a temperature of $200^{\circ} \mathrm{C}$ using thermogravimetric analysis. $10 \%$ of this UHMWPE/ULMWPE material is melt mixed with 90\% UHMWPE material using twin screw extruder within a temperature range of $190^{\circ} \mathrm{C}-220^{\circ} \mathrm{C}$ along with a screw speed adjusted to $150 \mathrm{rpm}$ (Figure 14). The extracted pellets are subjected to injection molding within a temperature of $220^{\circ} \mathrm{C}-$ $230^{\circ} \mathrm{C}$ so that they are converted into rectangular blocks. 


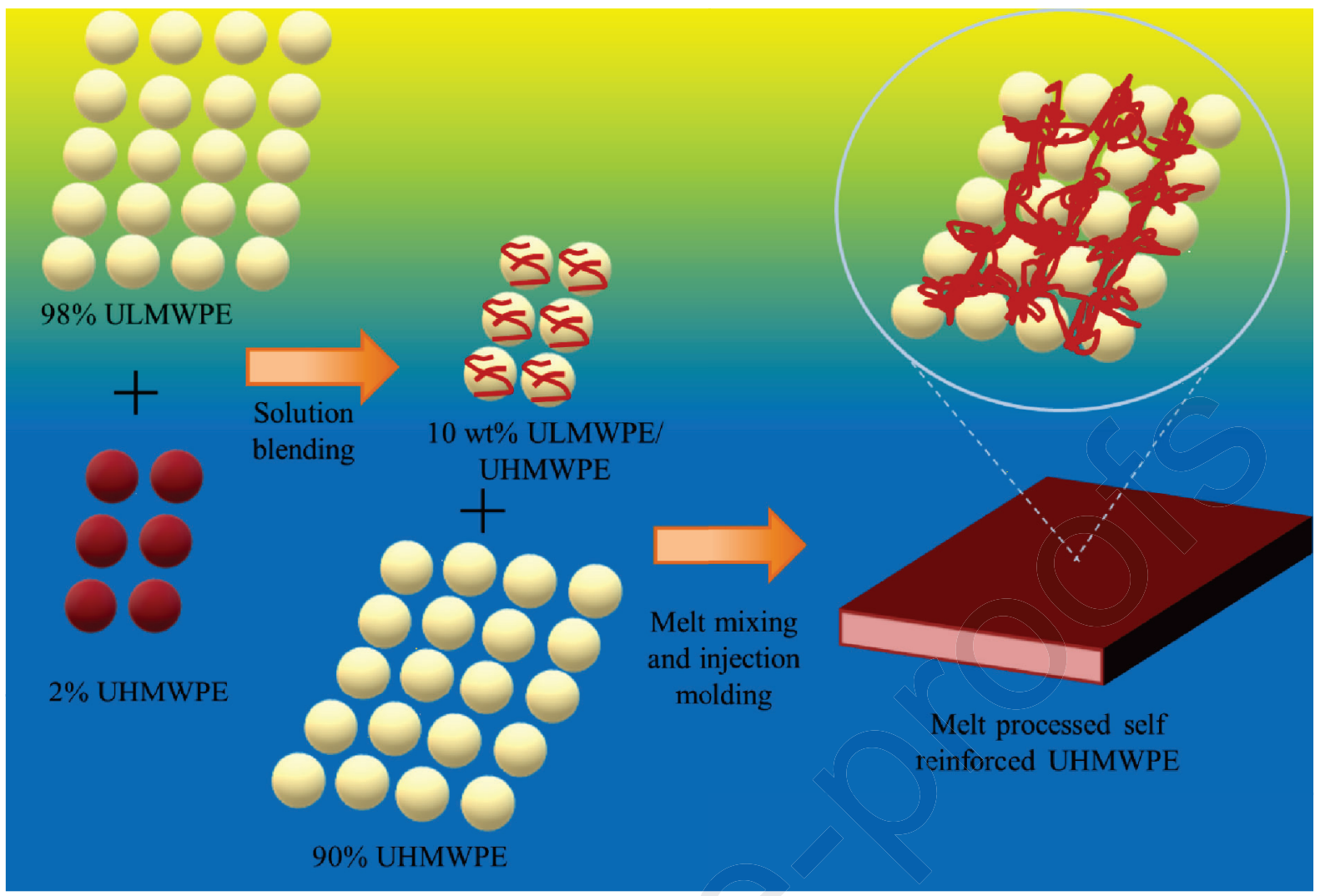

Figure 14: Schematic representation of melt processed self-reinforced UHMWPE.

The melt processed UHMWPE shows remarkable improvement in tensile strength (UTS) and young modulus (E) compared to that of compression molded UHMWPE, it increases from $\mathrm{UTS}=41.6 \pm 1.4 \mathrm{MPa} \& \mathrm{E}=662.7 \pm 24 . .1 \mathrm{MPa}(\mathrm{CM}-\mathrm{UHMWPE})$ up to $\mathrm{UTS}=65.5 \pm 3.1 \mathrm{MPa}$ $\& \mathrm{E}=1248.7 \pm 45.3 \mathrm{MPa}[100]^{\prime}[101]$. The coefficient of friction of MP-UHMWPE $(0.15 \pm$ $0.03)$ shows slightly lower values compared to that of CM- UHMWPE $(0.18 \pm 0.03)$, along with a lowered wear rate from $10.0 \pm 0.4 \mathrm{mg} / \mathrm{MC}$ (CM-UHMWPE) to $7.1 \pm 0.3 \mathrm{mg} / \mathrm{MC}$ (MPUHMWPE). The biocompatibility of material assessed using incubating fibroblast shows better adhesion of cells on MP-UHMWPE compared to that of CM-UHMWPE evaluated by MMT assay of cells[102,103]. Morphological structure explains that the shish-kebabs structures are formed in ULMWPE region and highly oriented lamellae are formed in UHMWPE region leading to highly crystalline regions capable of reducing structural defects in material as well as wear of implant material[2,104]. The functionalized properties of melt processed and self-reinforced UHMWPE/ULMWPE material comprises of improved tensile 
strength, tribological properties, biocompatibility along with reduced structural defects enable the wide application of material in knee joint implants majorly for younger and more active patients[105].

Annett Dorner Reisel et al studied and explained the utilization of diamond like carbon coatings on surface of CoCrMo alloys to reduce wear of alloy and UHMWPE counter face. According to studies of Jacobs et al, it has been recorded that the wear of the metallic alloys results in release of $\mathrm{Co}^{2+}$ ions which are harmful for tissues in human body, leading to a possibility of inflammation vitro[106]. The DLC coatings deposition is achieved by plasma decomposition of gaseous hydrocarbon[107], with anode and cathode voltage between 30$300 \mathrm{~V}[108]$, and varying thickness of the deposited thin film $(0.8 \mu \mathrm{m}, 2.7 \mu \mathrm{m}, 4.5 \mu \mathrm{m})$. The testing of the coated material reported that the increase in thickness of coating resulted in more wear of the UHMWPE material leading to surface cracks due to cyclic tension, whereas $2.7 \mu \mathrm{m}$ and $0.8 \mu \mathrm{m}$ DLC coated surfaces showed comparatively better performance than uncoated metal alloys. A parallel study demonstrated that the wear of material is also dependent on quality of polymer substance used as a counterpart and processing it has applied thoroughly[109]. Hence investigation determines the optimum thickness of DLC film to sustain wear resistance of biomaterial used in joint replacement.

A study regarding the use of carbon nano fillers (CNF) along with paraffin oil is demonstrated by Samy Yousef et al, study explains about the use of $0.5-2 \mathrm{wt} \%$ carbon nano fillers and $2 \%$ paraffin oil to enhance the wear resistance of material. The carbon nano fillers are obtained by ball milling mod of short carbon fibers (1\%), mixed with paraffin oil $(2 \%)$ by ball milling and twin screw extruder[110] at a compression molding temperature of $200^{\circ} \mathrm{C}$, along with pressure adjusted to $20 \mathrm{MPa}$ for duration of $20 \mathrm{~min}[111]$. According to experimental study, it has been recorded that the UHMWPE/PO/CNF composite manufactured by ball milling process has better crystallinity $(51.2 \%)$ and highest melting 
temperature $\left(135.52^{\circ} \mathrm{C}\right)$. The comparison of $\mathrm{UPC}_{1.0} \mathrm{BM}$ and $\mathrm{UPC}_{1.0} \mathrm{EX}$ is shown in table 9 [112].

Table 9: Tribological properties and wettability of U/ UP/ UPC composites

\begin{tabular}{|l|l|l|l|l|l|}
\hline Sample & $\begin{array}{l}\text { Average } \\
\text { roughness } \\
(\boldsymbol{\mu m})\end{array}$ & $\begin{array}{l}\text { Contact } \\
\text { angle }(\mathbf{0})\end{array}$ & $\begin{array}{l}\text { Wear test }\left(\mathbf{m m}^{\mathbf{3}} \mathbf{\text { N.m }}\right) \\
\text { in natural lubricant }\end{array}$ & $\begin{array}{l}\text { Melting } \\
\left.\text { Temperature } \mathbf{~}^{\mathbf{0}} \mathbf{C}\right)\end{array}$ & $\begin{array}{l}\text { Crystallinity } \\
(\%)\end{array}$ \\
\hline $\mathrm{U}$ & 0.21 & 72 & $14.7 \times 10^{-6}$ & - & - \\
\hline $\mathrm{UP}$ & 0.26 & 80 & $10.4 \times 10^{-6}$ & 134.90 & 48.5 \\
\hline $\mathrm{UPC}_{1.0} \mathrm{BM}$ & 0.53 & 85.36 & $2.4 \times 10^{-6}$ & 135.52 & 51.2 \\
\hline $\mathrm{UPC}_{1.0} \mathrm{EX}$ & 0.77 & 79.8 & $17.08 \times 10^{-6}$ & 134.33 & 50.5 \\
\hline
\end{tabular}

$\mathrm{U}=$ pure UHMWPE,

$\mathrm{UP}=\mathrm{UHMWPE}$ and paraffin oil composite,

$\mathrm{UPC}=\mathrm{UHMWPE}$, paraffin oil and nano filler carbon composite

It has been recorded that increment in concentration of CNF composite results in increased stiffness (hardness and tensile strength), also stress and strain at yielding point increases with increase in concentration from UPC 0.5 to UPC 1 , where further increase in concentration leads to fracture of the biomedical implant. Hence the observations recorded can be concluded as $\mathrm{UPC}_{1.0} \mathrm{BM}$ shows the optimum properties of material, with improved tribological properties and ductility, whereas decrease in wettability is observed due to increase in surface roughness[113], enhanced properties considering wear resistance and biocompatibility[114] which enables application of material in total joint arthroplasty[112].

\subsubsection{Bone tissue engineering}


The evolvement of medical implants has started with the study of bone tissue engineering, which comprises of the materials available for making needful alterations in case of replacement or regeneration regarding bone and tissues capable of exhibiting numerous applications in designing prosthesis. The various attempts are analysed globally to find the compatible materials that can be used for regeneration of bone and tissue as it is a diverse field of study that is capable of finding a solution to globally faced problems due to various modes of accidents or natural calamities.

An approach to develop a material of artificial articular cartilages and materials for prosthesis has been studied by Alexandra H. C. Poulsson et al using a polymers of UHMWPE and polystyrene (PS), functionalization of UHMWPE resulted in improved cell adhesion and wear resistance by attachment of polar groups on polymer surface. Prior to functionalization of the material, it is treated with methanol by sonication technique for duration of $20 \mathrm{~min}$. Further treatment of substrate with doubly distilled water for $20 \mathrm{~min}$ as well as treatment with few drops of acetone is carried out, in order to keep the substrate floating during cell culture. The functionalization of material is achieved using a UV/ozone reactor, the surface is treated with high intensity mercury lamp at $1120 \mu \mathrm{W} / \mathrm{cm}^{2} \mathrm{kept}$ at distance of $3 \mathrm{~cm}$ in atmospheric conditions, whereas the lamp is warmed 1 hour prior to the experiment such that proper transition of UV radiations at a wavelength of $184.9 \mathrm{~nm}$ and $253.7 \mathrm{~nm}$ is verified[115]. The surface treatment resulted in lowered contact angle of the material; it lowers the contact angle from $83^{\circ}$ to $73^{\circ}$ with a UV/ozone treatment for duration of 10 min, whereas it was experimentally observed that no significant decrease in contact angle appears due to increased contact time. Proliferation and cell adhesion properties of the material were determined by alamarBlue assay (Figure 15), the readings concluded that the surfaces with $19 \%$ oxygen shows better cell adhesion when monitored for a duration of 21 
days as well as remarkable increase in cell density was observed after 10 days of treatment[116].

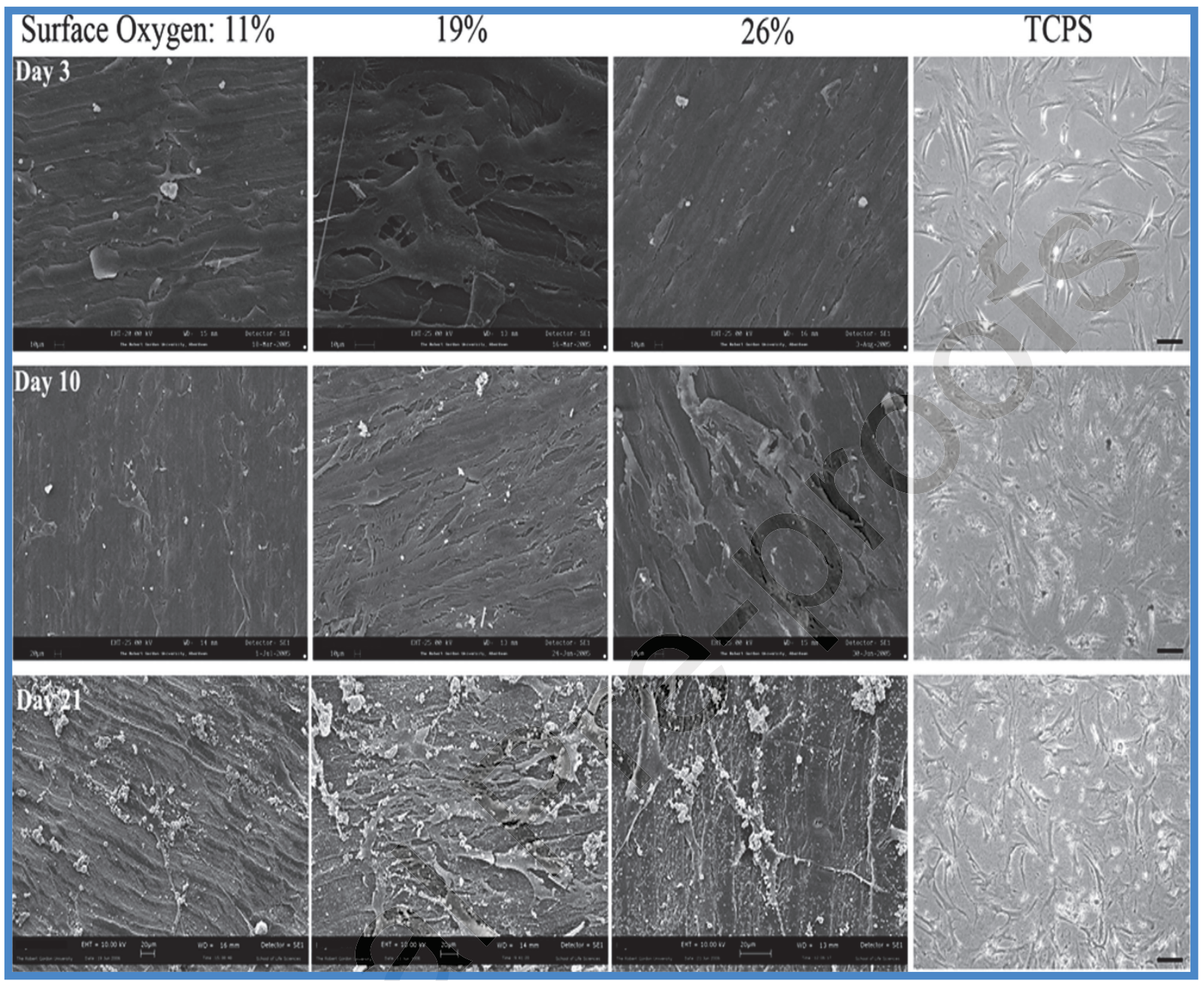

Figure 15: SEM images for cell growth on UHMWPE surface observed after treatment for 3 days, 10 days, and 21 days.

An innovative methodology for modifications in medical implant has been studied by Y. Shikinami and H. Kawarda et al, where they modified the material by coating of melted linear low density polyethylene material (LLDPE) on surface of UHMWPE at $200^{\circ} \mathrm{C}$ using extrusion technique and converted the material into a three dimensional fabricated structure. The sample having a very steep tangent slope shows a tensile strength of $7 \mathrm{MPa}$ when applied with $7 \%$ strain where profile resembles $\mathrm{S}$ shaped curve, the sample with a low slope of tangent shows $\mathrm{J}$ shaped stress strain profile and barely sustained $3 \mathrm{MPa}$ in $\mathrm{X}$ axis direction 
and $1 \mathrm{MPa}$ in $\mathrm{Y}$ axis direction with $40 \%$ strain[117]. A slight modification by spraying of HA material and corona discharged material lowers the contact angle of the substrate from $70^{\circ}$ to $33^{\circ}$, resulting in appropriate wettability of the substrate (Figure 16), when the testing was carried out after duration of 2 weeks HA coating was sustained as it was bonded with the LLDPE, demonstrating the good surface compatibility and bonding ability for biomaterials in medical implants.

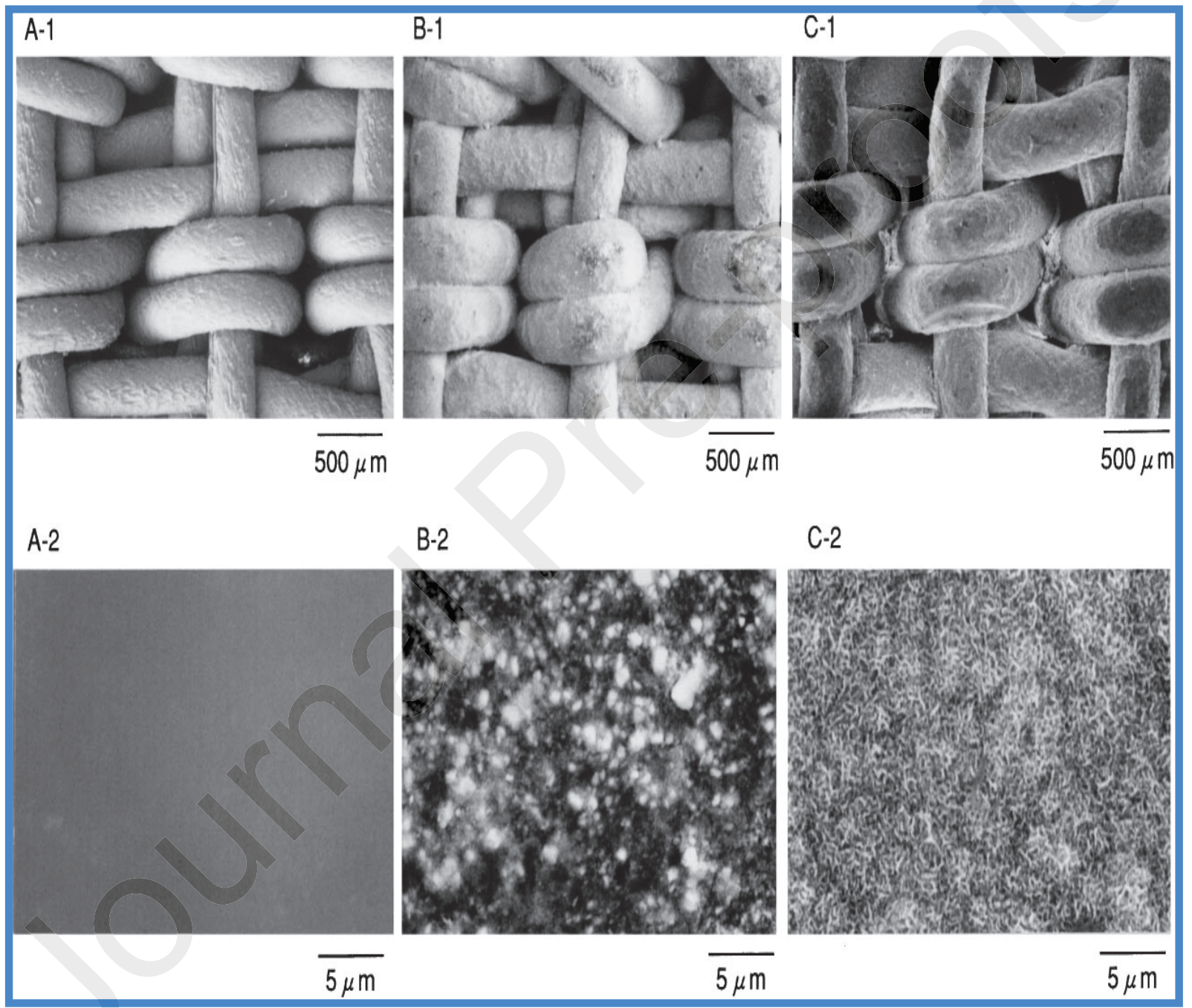

Figure 16: Surface of UHMWPE surface (a) virgin UHMWPE, (b) Hydroxyapatite sprayed surface, (c) sample surface post 2 week treatment with stimulated body fluid. [117] The cell tissues were observed to be penetrating inside the material after adulteration of 4 weeks, on HA and corona discharge treated material the failure load observed was $1.2 \mathrm{kgcm}^{-2}$ and $1.7 \mathrm{~kg} \mathrm{~cm}^{-2}$ for 4 and 8 weeks respectively. Also, the bio-ceramics and corona discharge 
treated materials shows good surface bioactivity and surface biocompatibility[118], enabling it's application in osteosynthesis and prosthesis[117].

Alex Reising et al demonstrated a distinct way to functionalize a combination of UHMWPE and polytetrafluoroethylene (PTFE) material with nanostructured titanium using an ionic plasma deposition technique, the process was executed in vacuum conditions for formation of controllable nanostructured surface capable of cell adhesion. The coated samples are cleaned using deionized water within a sonicator with $70 \%$ ethanol for duration of $10 \mathrm{~min}$, followed by drying at $65^{\circ} \mathrm{C}$ in presence of UV light for 1 hour. The samples were subjected to cytocompatibility test, the results obtained suggest that the material exhibits improved long term osteoblast function including deposition of calcium containing materials[119]. The analysis of SEM images of the material for a week shows increment in osteoblast function of material with increasing time period, resulting in increased osteoblast density[120]

Ankur Gupta et al studied the compression molded UHMWPE/HA/Alumina oxide/carbon nanotubes hybrid composite for hard tissue replacement in human body, the study was on performance of hybrid material containing 2-5 wt $\% \mathrm{HA}, 2-5 \mathrm{wt} \% \mathrm{Al}_{2} \mathrm{O}_{3}, 2-4$ wt $\%$ CNT fabricated via compression molding. In the composite material, HA acts as bioceramic for osteointegration process, Aluminium oxide serves as bio inert and wears resistive material along with CNT enhancing mechanical, thermal and electrical properties. The hybrid material is manufactured using $\mathrm{HA}(-30-50 \mathrm{~nm}), \mathrm{Al}_{2} \mathrm{O}_{3}(-99.9 \%$ purity), CNT ( $>95 \%$ purity) blended mechanically for duration of 6 hours, followed by compression molding of the powder at $180^{\circ} \mathrm{C}$ at $7.5 \mathrm{MPa}$ for duration of $45 \mathrm{~min}$. The mechanical properties of material were evaluated using nanoindentation technique, the noted results show that virgin UHMWPE shows hardness and elastic modulus of $70.5 \pm 8.7 \mathrm{MPa}$ and $1.45 \pm 0.15 \mathrm{GPa}$ respectively. The increase in only HA content ( $2 \%$ to $5 \%)$ results in declined hardness and 
elastic modulus of the material form $55.4 \pm 10.9 \mathrm{MPa}$ to $39.7 \pm 7.7 \mathrm{MPa}$ and $0.91 \pm 0.17 \mathrm{GPa}$ to $0.61 \pm 0.12 \mathrm{GPa}$ respectively, contradictorily increase in alumina content results in increased hardness (from $69.9 \pm 14.1 \mathrm{MPa}$ to $79.0 \pm 11.3 \mathrm{MPa}$ ) but slight decrease in elastic modulus (from $1.53 \pm 0.31 \mathrm{GPa}$ to $1.51 \pm 0.22 \mathrm{GPa}$ ). Figure 17 demonstrates the effect of reinforcement on surface morphology of UHMWPE composite.

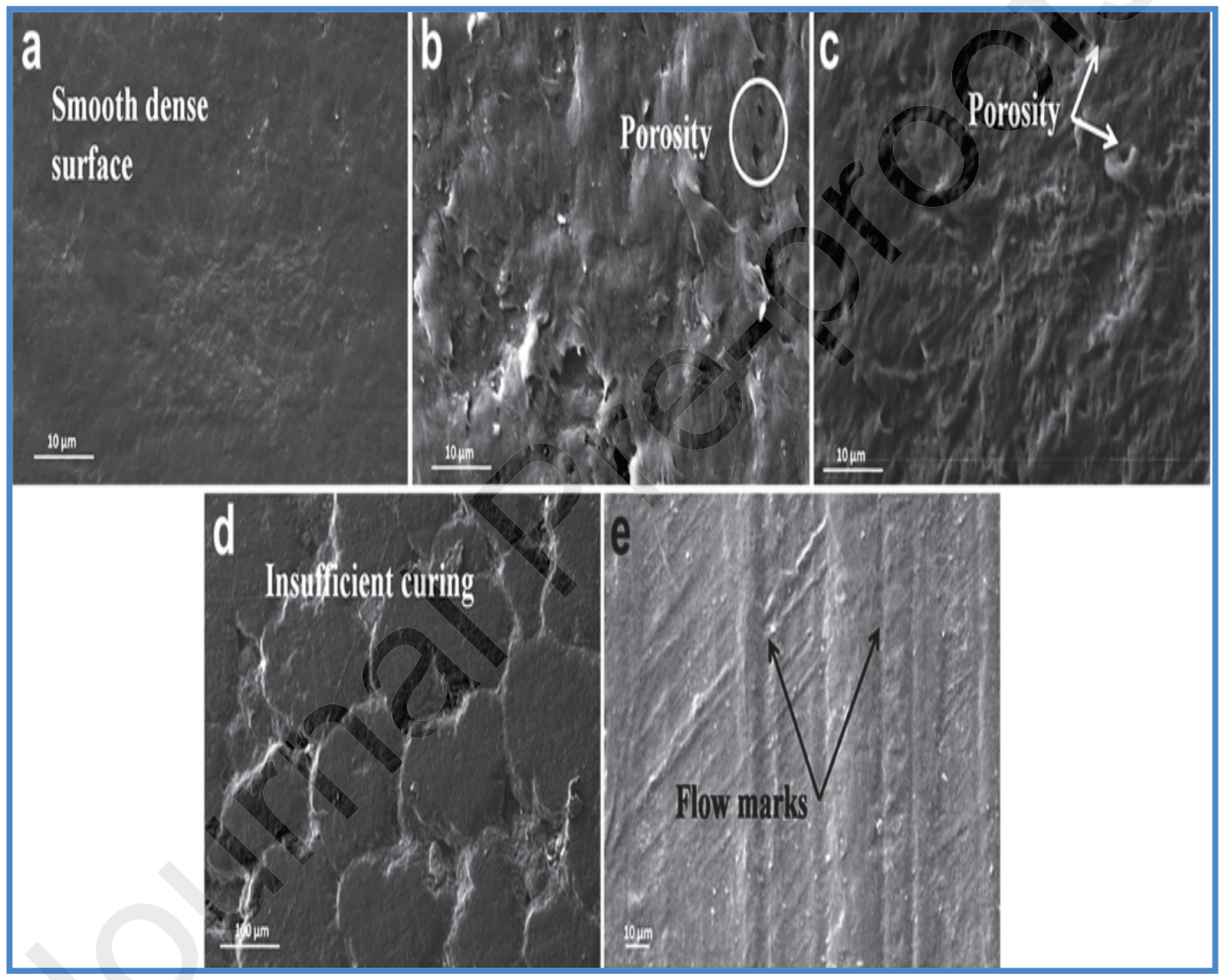

Figure 17: SEM images for surface of (a) untreated UHMWPE, (b) 98\%UHMWPE/ 2\%HA, (c) $95 \%$ UHMWPE/ 5\%HA, (d) 98\%UHMWPE/ 2\% $\mathrm{Al}_{2} \mathrm{O}_{3}$, (e) 95\%UHMWPE/ 5\% $\mathrm{Al}_{2} \mathrm{O}_{3}$ The optimum results for the material is obtained using a combination of UHMWPE/ $2 \% \mathrm{HA} /$ $5 \% \mathrm{Al}_{2} \mathrm{O}_{3} / 2 \% \mathrm{CNT}$, the observations noted for the combination shows hardness of $54.7 \pm$ 10.1 $\mathrm{MPa}$ and elastic modulus of $0.97 \pm 0.17 \mathrm{GPa}$ along with an elasticity index of 0.275 for the material resulting in better mechanical properties of the material [121]. 
An alternate innovative approach to use hydroxyapatite nano-rods for bone tissue generation has been studied by A. Joseph Nathanael et al, their elaborative studies demonstrate the effect of $10 \%$ hydroxyapatite nanorods on mechanical properties of material. Experimental hydroxyapatite was manufactured using $\mathrm{Ca}\left(\mathrm{NO}_{3}\right)_{2}$ and $\left(\mathrm{NH}_{4}\right)_{2} \mathrm{HPO}_{4}$ maintaining a molar ratio of 1:0.6 in presence of thorough stirring assembly and temperature adjusted to $180^{\circ} \mathrm{C}$ for reaction, followed by cooling of precipitate and crushing of granules at $600^{\circ} \mathrm{C}$ for duration of 2 hours. The hydroxyapatite $(10 \%)$ obtained is then reinforced with UHMWPE, blending of composite is achieved using high speed rotating kneader at $180^{\circ} \mathrm{C}$ for $20 \mathrm{~min}$, followed by conversion into reinforced UHMWPE rods using horizontal injection moulding machine[122]. The material possess improved mechanical properties, statistical analysis of material is tabulated in table 11. The improved mechanical properties, abrasion resistance along with biocompatibility of HA enable the application of functionalized material in bone tissue generation[123].

Table 10: Mechanical properties of hydroxyapatite reinforced UHMWPE materials[122].

\begin{tabular}{|c|c|c|c|}
\hline Substrate & Young modulus (GPa) & Yeild strength (MPa) & Wear rate (\%) \\
\hline UHMWPE Untreated & 0.85 & 38.64 & 0.02177 \\
\hline UHMWPE + 10\% HA & 3.79 & 43.02 & 0.03075 \\
\hline
\end{tabular}

Chenbo Meng et al demonstrated an innovative method of using organo-silicon compound as coupling agent having application in medical implants due to improved hydrophilicity, biocompatibility, and proliferation on cell walls[124]. The vinyl triethoxysilane (VTEOS) treatment is related to grafting of organo-silicon compound on UHMWPE surface by air plasma treatment, in presence of situ to develop a plasma induced in-situ grafting. The silane containing vinyl group and three alkoxyl group are grafted on the macromolecular chain through vinyl group by peroxide initiation and then alkoxyl group hydrolyze to form hydroxyl groups for crosslinking. The functionalized material was 
manufactured using air plasma treatment of vinyl triethoxysilane (VTEOS) soaked and subsequently compression molded UHMWPE using RF flow discharge apparatus (Figure 18), treated samples were cleansed employing a ethanol soaking treatment for 24 hours to remove the unfixed VTEOS from the material. The treatment resulted in enhancing hydrophilicity of material by lowering contact angle significantly from $92.8^{\circ}$ (Untreated UHMWPE) to $47.5^{\circ}$ (VTEOS treated UHMWPE), surface area of material enhances from $27.5 \mathrm{mN} / \mathrm{m}$ to $55.2 \mathrm{mN} / \mathrm{m}$. The viability of cell adhesion and proliferation rate was assessed by MTT assay, the readings recorded signifies improved cell adhesion, biocompatibility and drastically improved proliferation rate compared to that of untreated UHMWPE as the functionalization effects increases with increase in culture time. The improved properties of the functionalized material increases marketability of material for advanced biocompatible medical implants[124].

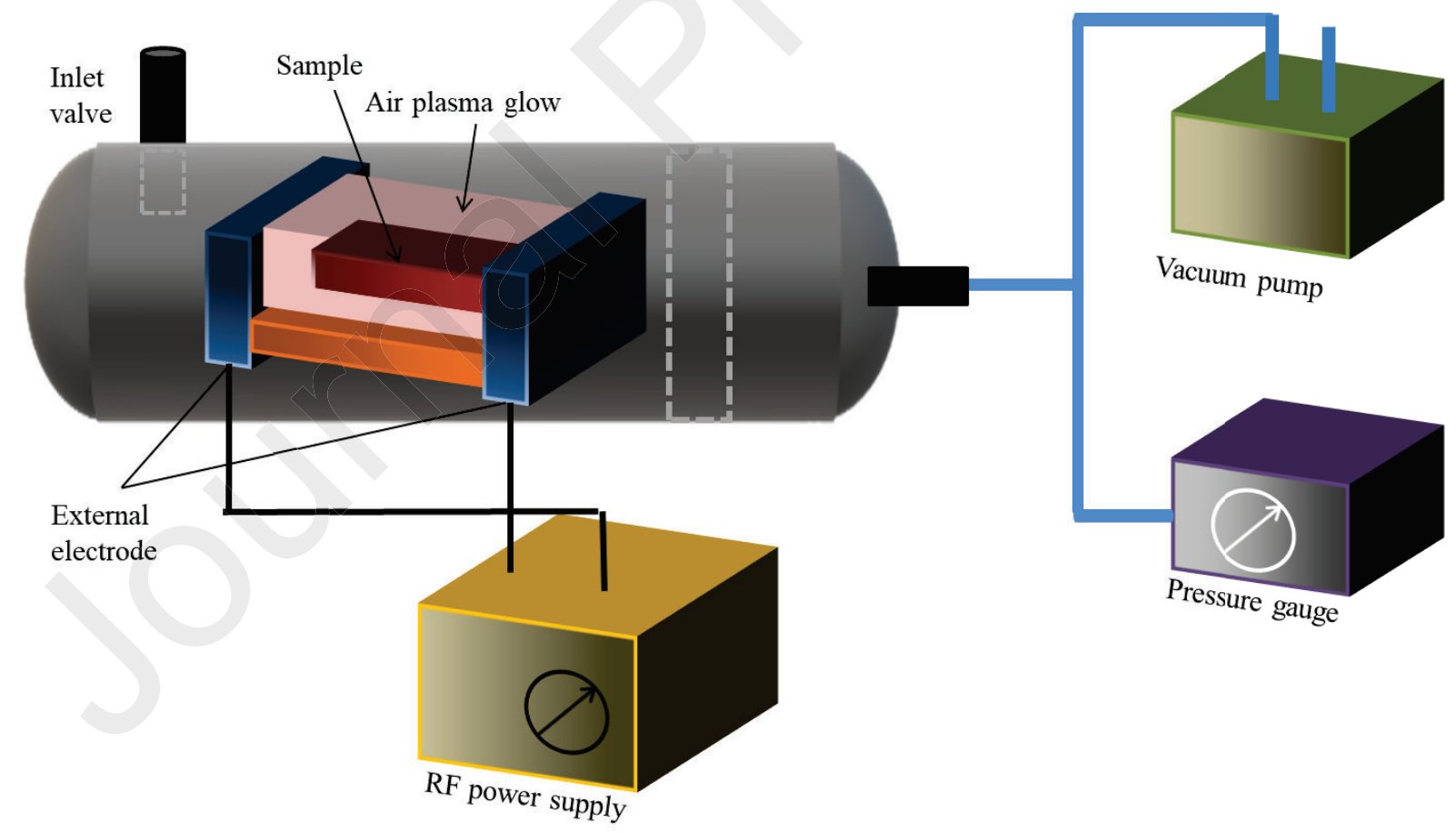

Figure 18: Schematic diagram for VTEOS treatment using air plasma technique 
Similar study to improve wettability and biocompatibility of material was studied by Gema Del Prado et al, demonstrating the reinforcement of UHMWPE with 3\% multi walled carbon nanotubes (MWCNTs) as a reinforcing agent. The composite is manufactured using hot pressure forming, resulting in reduced bacterial adherence which happens to be a key factor for implant related infection. The study focuses on two types of MWCNTs - catalytic carbon vapour deposited MWCNTs (Purity > 90\%) and arc discharge MWCNTs, the reinforcement was imparted in UHMWPE using hot platen press method at $155^{\circ} \mathrm{C}$ and pressure of $15 \mathrm{MPa}$ for duration of $30 \mathrm{~min}$. Nanoindentation test was carried out to determine surface roughness and hardness of the material, both the materials exhibited comparable and similar properties with a peak at $600 \mathrm{~nm}$, whereas contact angle was recorded to increase from $81.5^{\circ} \pm 5^{\circ}$ (Untreated UHMWPE) till $93^{\circ} \pm 2^{\circ}(3 \%$ MWCNTs treated sample $)[3,125]$. The UHMWPE/MWCNTs composites exhibit better anti adherence properties, where arc discharged MWCNTs exhibit's slightly better properties compared to that of carbon vapour deposited (about 0.25 times better performance) which is capable of eliminating the possibility of implant infections.

An extraordinary method for modification of UHMWPE in bone implants has been studied by A. Riveiro et al, investigating the performance of carbon coated materials[126,127] (thickness $50 \mu \mathrm{m}$ to $100 \mu \mathrm{m}$ ) deposited using low velocity gas jet on UHMWPE followed by a laser treatment. The cleaning of substrate is carried out by undergoing ultrasonic treatment in presence of ethanol for separating the unstuck carbon particles from the surface of UHMWPE. The treated samples are tested for three wavelengths (1064 nm, $532 \mathrm{~nm}$, and $355 \mathrm{~nm}$ ) for average surface roughness and average contact angle of the treated material, results recorded after the testing is tabulated in table 10. According the results obtained, it can be inferred that the carbon coated substrate shows enhanced smoothness and hydrophilic properties (due to lowering in contact angle)[128] with lowering 
the wavelength of laser radiation. The functionalized material shows numerous applications in improving the surface properties for bone implants used during joint replacement operations[129].

Table 11: Average roughness and contact angle of laser treated, carbon coated UHMWPE

\begin{tabular}{|l|l|l|}
\hline Sample & Average roughness $(\mu \mathrm{m})$ & Average contact angle $\left(^{\circ}\right)$ \\
\hline Untreated UHMWPE & $2.3 \pm 0.4$ & $82 \pm 5$ \\
\hline $355 \mathrm{~nm}$ treated & $2.3 \pm 0.7$ & $75.2 \pm 10$ \\
\hline $532 \mathrm{~nm}$ treated & $1.7 \pm 0.5$ & $57.6 \pm 6$ \\
\hline $1064 \mathrm{~nm}$ treated & $1.9 \pm 0.6$ & $56.8 \pm 7$ \\
\hline
\end{tabular}

A similar study investigated by Shardul Atul Bhusari et al demonstrated the use of carbonaceous compounds[130] as reinforcement for HDPE and UHMWPE composite exhibiting modified mechanical properties having vital application in bone tissue engineering. The functionalization process comprises of a polymer matrix $(60 \%$ HDPE and 40\% UHMWPE) and reinforcing agent (modified graphene oxide) blended in various concentrations of reinforcement $(0.5 \%, 1 \%$ and $3 \% \mathrm{mGO})$ melt extruded[131] at temperature of $220^{\circ} \mathrm{C}$ for duration of $10 \mathrm{~min}$, whereas the extruded nanocomposites are subjected to injection molding at $220^{\circ} \mathrm{C}$ along with pressure conditions adjusted to $12 \mathrm{MPa}$ for duration of $10 \mathrm{~min}$ as well as mold temperature was adjusted to $100^{\circ} \mathrm{C}$ [132]. The modified samples were tested for rheological (stress control discovery hybrid rheometer) and mechanical properties (INSTRON 5967), where the resulted achieved are tabulated in table 12.

Table 12: Rheological and Mechanical properties analysis for GO reinforced with UHMWPE[132]

\begin{tabular}{|l|l|l|lr|l|}
\hline Sample & $\mathbf{T}_{\mathrm{m}}\left({ }^{\circ} \mathrm{C}\right)$ & Crystallinity (\%) & Tensile & strength & Elastic modulus (MPa) \\
\hline
\end{tabular}




\begin{tabular}{|l|l|l|l|l|}
\hline & & & $(\mathbf{M P a})$ & \\
\hline $\mathrm{HU}$ & 131.0 & 44.8 & $29.5 \pm 0.6$ & $645.7 \pm 41.6$ \\
\hline $0.5 \mathrm{GO}$ & 130.8 & 46.4 & $29.1 \pm 2.5$ & $620 \pm 27.5$ \\
\hline 0.5 & 131.5 & 44.1 & $56.7 \pm 0.7$ & $961.3 \pm 44.7$ \\
\hline $1 \mathrm{GOO}$ & 133.5 & 41.5 & $56.1 \pm 3.7$ & $787.7 \pm 53.6$ \\
\hline $1 \mathrm{mGO}$ & 131.9 & 59.4 & $65.1 \pm 3.4$ & $908 \pm 58.1$ \\
\hline $3 \mathrm{GO}$ & 131.2 & 40.6 & $55.2 \pm 5.3$ & $805.3 \pm 70.3$ \\
\hline $3 \mathrm{mGO}$ & 132.2 & 39.8 & $56.3 \pm 1.8$ & $835.0 \pm 104.7$ \\
\hline
\end{tabular}

The cytocompatability of composite has been studied using SEM images after 3 days of treatment to composite material; the result achieved from the SEM images clearly determines presence of similar amount of cell growth on material surface. Hence the improved mechanical, rheological and cell attachment along with proliferation satisfies the use of this material as a potential biomaterial for bone tissue engineering[132,133].

\subsection{Morphology of reinforced composite:}

The morphological investigation of the reinforced composites is analysed in order to study the surface behaviour of material, it is significantly important to predict mechanical properties based on morphological structure of a particular composite. In case of hydroxyapatite containing filler in HDPE/UHMWPE composites, the HA particles were found to be highly intact with the polymer indicating good mechanical interlocking in morphological structure. The enhanced morphology of the composite due to immersion of HA particles results in good mechanical properties of the material, it exhibits a substantial reduction in bulk deformation by nearly $45 \%$ [134]. A study conducted by brown et al explains the dependence of morphology for reinforcing monocyclic carbon nanotubes on 
substrate shows good mechanical response of the biomaterial, along with the state of aggregation of nanotubes in some case. Long, straight, well-dispersed nanofilaments induced the production of more tumor necrosis factor-alpha and reactive oxidative species than highly curved and entangled aggregates. These investigators also described incomplete uptake or frustrated phagocytosis induced by CNT[135]. An investigation carried out my Ming Li et al shows the morphological behaviour of graphene oxide/hydroxyapatite coatings for biological applications. The results obtained through ESEM demonstrates the reinforcing of graphene oxide in the composite material enhances the mechanical stability of material, the small and less cracks in modified substrate is evident for the concluded results. The possible reasons for formation of cracks on the substrate is due to drying stress within the coatings, thermal expansion between the coating and substrate during processing[136]. The treatment of samples after removal from suspension by sintering process or evaporation of ethanol might be a possible reason for formation of cracks on the substrate. Graphene oxide is observed to exhibit nanostructured folding and scrolling morphology at the edges of reinforced substrate[137].

\section{Conclusion and future scope}

The increase in various medical causalities along with continuously increasing of global aged population has lead researchers to develop a tensile and biocompatible biomaterial having potential application as medical implant. The thorough studies done by researchers have found some materials like UHMWPE that serves as a principal material for manufacturing of biomaterials. This material has observed with some limitations as limited age of medical implant, wear resistance whereas an alternative solution to control the ageing of implant has been developed, focused on reinforcement of UHMWPE using various fibres or chemicals capable of functionalizing material resulting in enhanced properties of UHMWPE. The functionalized properties comprise of mechanical properties, wear 
resistance, biocompatibility, cytocompatibility, wettability, surface properties of biomaterial. The detailed study of various reinforcement materials along with surface treatments can be concluded as utilization of reinforcing material to achieve a desired property depending upon end application of the material. As discussed in review, hydroxyapatite is widely utilized to ameliorate mechanical properties of UHMWPE and controlled hardness of material, Carbon nanotubes has potential application to increase mechanical properties drastically in addition to maintaining hydrophobicity and antibacterial properties of material which has wide application in case of anti-infecting medical implant, reinforcement using modified graphene oxide having excellent mechanical properties along with cell growth and surface adhesion of functionalized material having diverse application in bone tissue engineering, Vitamin E acts as anti-oxidant to eliminate oxidation of material which is determined as influential cause for wear of medical implant successively leading to osteolysis, DLC coatings are essential reinforcement in enhancing wear resistance of UHMWPE. The morphology of the reinforced substrate plays an important role in determining the mechanical stability as well as thermal expansions of material, it provides a clear insight about the wear characteristics which eventually is most significant factor to determine the longevity of the biomedical implant. The research has also been focused on improving the surface properties of material such as smoothness, coefficient of friction, biocompatibility and haemocompatibility to improve the aesthetic look in addition to potential application as user friendly and cost-effective medical implant. The future of the medical implant industry is focusing on providing the user friendly and cost-effective solutions globally to cope up with the causalities and globally faced orthopaedic problems using functionalized UHMWPE.

\section{Acknowledgement}

The authors would like to thank Dr. C. P. Ramanarayanan, Vice-Chancellor, DIAT (DU), Pune, and Prof. R. V. Adivarekar, Head of Department of Fibres and Textile Processing 
Technology, ICT Mumbai, for constant encouragement and support. The authors would also

like to acknowledge Mr. Swaroop Gharde, Mr. Rushikesh Ambekar, Mr. Jay Korde, Mr. Prakash Gore for technical discussions and support. I would like to dedicate this review paper to my father Mr. Avinash Patil.

\section{References}

[1] A.L. Bruck, K.S.K. Karuppiah, S. Sundararajan, J. Wang, Z. Lin, Friction and wear behavior of ultrahigh molecular weight polyethylene as a function of crystallinity in the presence of the phospholipid dipalmitoyl phosphatidylcholine, J. Biomed. Mater. Res. - Part B Appl. Biomater. 93 (2010) 351-358. https://doi.org/10.1002/jbm.b.31587.

[2] L. Xu, C. Chen, G.J. Zhong, J. Lei, J.Z. Xu, B.S. Hsiao, Z.M. Li, Tuning the superstructure of ultrahigh-molecular-weight polyethylene/low-molecular-weight polyethylene blend for artificial joint application, ACS Appl. Mater. Interfaces. 4 (2012) 1521-1529. https://doi.org/10.1021/am201752d.

[3] G. del Prado, F.J. Pascual, P. Castell, D. Molina-Manso, I. Mahillo, J. Esteban, J.A. Puértolas, Influence of carbon nanotubes structures embedded in UHMWPE on bacterial adherence, Int. J. Polym. Mater. Polym. Biomater. 67 (2018) 934-941. https://doi.org/10.1080/00914037.2017.1393684.

[4] P. Rastogi, B. Kandasubramanian, Review of alginate-based hydrogel bioprinting for application in tissue engineering, Biofabrication. 11 (2019) 42001. https://doi.org/10.1088/1758-5090/ab331e.

[5] R.S. Ambekar, B. Kandasubramanian, Progress in the Advancement of Porous Biopolymer Scaffold: Tissue Engineering Application, Ind. Eng. Chem. Res. 58 (2019) 6163-6194. https://doi.org/10.1021/acs.iecr.8b05334.

[6] A. Davis, B. K., B. K., Bioactive Hybrid Composite Membrane with Enhanced 
Antimicrobial Properties for Biomedical Applications, Def. Sci. J. 66 (2016) 434. https://doi.org/10.14429/dsj.66.10218.

[7] J.M. Korde, B. Kandasubramanian, Biocompatible alkyl cyanoacrylates and their derivatives as bio-adhesives, Biomater. Sci. (2018).

https://doi.org/10.1039/C8BM00312B.

[8] N. Manhas, K. Balasubramanian, P. Prajith, P. Rule, S. Nimje, PCL/PVA nanoencapsulated reinforcing fillers of steam exploded/autoclaved cellulose nanofibrils for tissue engineering applications, RSC Adv. 5 (2015) 23999-24008. https://doi.org/10.1039/c4ra17191h.

[9] K.S. Suhail, R.B.A. Raj, M. Hudlikar, K. Balasubramanian, Fabrication of Bioactive Nano Assimilated Polymeric Scaffold for the Metamorphosis of Organs or Tissues: Triumph, Confrontation and Prospective, J. Bionanoscience. 9 (2015) 167-180. https://doi.org/10.1166/jbns.2015.1295.

[10] A. Prasad, B. Kandasubramanian, Fused deposition processing polycaprolactone of composites for biomedical applications, Polym. Technol. Mater. (2019) 1-34. https://doi.org/10.1080/25740881.2018.1563117.

[11] N.A. Patil, B. Kandasubramanian, Biological and mechanical enhancement of zirconium dioxide for medical applications, Ceram. Int. (2019). https://doi.org/10.1016/j.ceramint.2019.10.220.

[12] P.D. UN Department of Economic and Social Affairs, Summary for Policymakers, World Popul. Prospect. 2017 Revis. 3 (2017) 53.

[13] K.A. Jockisch, S.A. Brown, T.W. Bauer, K. Merritt, Biological response to choppedcarbon-fiber-reinforced peek, J. Biomed. Mater. Res. 26 (2004) 133-146. https://doi.org/10.1002/jbm.820260202.

[14] J.M. Korde, B. Kandasubramanian, Fundamentals and Effects of Biomimicking 
Stimuli-Responsive Polymers for Engineering Functions, Ind. Eng. Chem. Res. 58 (2019) 9709-9757. https://doi.org/10.1021/acs.iecr.9b00683.

[15] R. Goud, R. Yadav, X. Wang, M. Naebe, B. Kandasubramanian, Mollusk-Inspired 3D Printing of Polycarbonate via Fused Deposition Modelling, in: Handb. Polym. Ceram. Nanotechnol., Springer International Publishing, Cham, 2020: pp. 1-12. https://doi.org/10.1007/978-3-030-10614-0_46-1.

[16] S.M. George, B. Kandasubramanian, Advancements in MXene-Polymer composites for various biomedical applications, Ceram. Int. (2019). https://doi.org/10.1016/j.ceramint.2019.12.257.

[17] D.C. Mears, Metals in medicine and surgery, Int. Met. Rev. 22 (2014) 119-155. https://doi.org/10.1179/imtr.1977.22.1.119.

[18] F. Escalas, J. Galante, W. Rostoker, P.S. Coogan, MP35N: A corrosion resistant, high strength alloy for orthopedic surgical impants: Bio-assay results, J. Biomed. Mater. Res. 9 (1975) 303-313. https://doi.org/10.1002/jbm.820090306.

[19] L. Fang, Y. Leng, P. Gao, Processing and mechanical properties of HA / UHMWPE nanocomposites, 27 (2006) 3701-3707. https://doi.org/10.1016/j.biomaterials.2006.02.023.

[20] J. Narayan, W.D. Fan, R.J. Narayan, P. Tiwari, H.H. Stadelmaier, Diamond, diamondlike and titanium nitride biocompatible coatings for human body parts, Mater. Sci. Eng. B. 25 (1994) 5-10. https://doi.org/10.1016/0921-5107(94)90193-7.

[21] D. Lahiri, R. Dua, C. Zhang, I. De Socarraz-Novoa, A. Bhat, S. Ramaswamy, A. Agarwal, Graphene nanoplatelet-induced strengthening of ultrahigh molecular weight polyethylene and biocompatibility in vitro, ACS Appl. Mater. Interfaces. 4 (2012) 2234-2241. https://doi.org/10.1021/am300244s.

[22] D.F. Farrar, A.A. Brain, The microstructure of ultra-high molecular weight 
polyethylene used in total joint replacements, Biomaterials. 18 (1997) 1677-1685. https://doi.org/10.1016/S0142-9612(97)00143-9.

[23] S.M. Kurtz, Composite UHMWPE Biomaterials and Fibres, in: UHMWPE Biomater. Handb. Ultra High Mol. Weight Polyethyl. Total Jt. Replace. Med. Devices Third Ed., 2015: pp. 249-258. https://doi.org/10.1016/B978-0-323-35401-1.00002-8.

[24] M. Lapcikova, M. Slouf, J. Dybal, E. Zolotarevova, G. Entlicher, D. Pokorny, J. Gallo, A. Sosna, Nanometer size wear debris generated from ultra high molecular weight polyethylene in vivo, Wear. 266 (2009) 349-355. https://doi.org/10.1016/j.wear.2008.06.005.

[25] J.J.A.M. Van Raay, P.M. Rozing, C.A. Van Blitterswijk, R.M. Van Haastert, H.K. Koerten, Biocompatibility of wear-resistant coatings in orthopaedic surgery in vitro testing with human fibroblast cell cultures, J. Mater. Sci. Mater. Med. 6 (1995) 80-84. https://doi.org/10.1007/BF00120412.

[26] C.S. Cummings, E.M. Lucas, J.A. Marro, T.M. Kieu, J.D. DesJardins, The effects of proton radiation on UHMWPE material properties for space flight and medical applications, Adv. Sp. Res. 48 (2011) 1572-1577. https://doi.org/10.1016/j.asr.2011.07.009.

[27] B.S. Heidari, S.M. Davachi, A.H. Moghaddam, J. Seyfi, I. Hejazi, R. Sahraeian, H. Rashedi, Optimization simulated injection molding process for ultrahigh molecular weight polyethylene nanocomposite hip liner using response surface methodology and simulation of mechanical behavior, J. Mech. Behav. Biomed. Mater. 81 (2018) 95105. https://doi.org/10.1016/j.jmbbm.2018.02.025.

[28] V.P. Poliakov, C.J. d. M. Siqueira, W. Veiga, I.A. Hümmelgen, C.M. Lepienski, G.G. Kirpilenko, S.T. Dechandt, Physical and tribological properties of hard amorphous DLC films deposited on different substrates, Diam. Relat. Mater. 13 (2004) 1511- 
1515. https://doi.org/10.1016/j.diamond.2003.11.031.

[29] V. Premnath, W.H. Harris, M. Jasty, E.W. Merrill, Gamma sterilization of UHMWPE articular implants: An analysis of the oxidation problem, Biomaterials. 17 (1996) 1741-1753. https://doi.org/10.1016/0142-9612(95)00349-5.

[30] A. Gigante, C. Bottegoni, V. Ragone, L. Banci, Effectiveness of Vitamin-E-Doped Polyethylene in Joint Replacement: A Literature Review, J. Funct. Biomater. 6 (2015) 889-900. https://doi.org/10.3390/jfb6030889.

[31] L. Costa, M.P. Luda, L. Trossarelli, E.M. Brach del Prever, M. Crova, P. Gallinaro, In vivo UHMWPE biodegradation of retrieved prosthesis, Biomaterials. 19 (1998) 13711385. https://doi.org/10.1016/S0142-9612(98)00013-1.

[32] S. Affatato, N. Freccero, P. Taddei, The biomaterials challenge: A comparison of polyethylene wear using a hip joint simulator, J. Mech. Behav. Biomed. Mater. 53 (2016) 40-48. https://doi.org/10.1016/j.jmbbm.2015.08.001.

[33] P. Massin, S. Achour, Wear products of total hip arthroplasty: The case of polyethylene, Morphologie. 101 (2017) 1-8. https://doi.org/10.1016/j.morpho.2016.06.001.

[34] M.P. Luda, L. Trossarelli, E.M. Brach del Prever, P. Gallinaro, M. Crova, L. Costa, Oxidation in orthopaedic UHMWPE sterilized by gamma-radiation and ethylene oxide, Biomaterials. 19 (2002) 659-668. https://doi.org/10.1016/s01429612(97)00160-9.

[35] E.M. Brach del Prever, A. Bistolfi, P. Bracco, L. Costa, UHMWPE for arthroplasty: Past or future?, J. Orthop. Traumatol. 10 (2009) 1-8. https://doi.org/10.1007/s10195008-0038-y.

[36] C.M. Chan, T.M. Ko, H. Hiraoka, Polymer surface modification by plasmas and photons, Surf. Sci. Rep. 24 (1996) 1-54. https://doi.org/10.1016/0167-5729(96)80003- 
3.

[37] P.L. Girard-Lauriault, F. Mwale, M. Iordanova, C. Demers, P. Desjardins, M.R. Wertheimer, Atmospheric pressure deposition of micropatterned nitrogen-rich plasmapolymer films for tissue engineering, Plasma Process. Polym. 2 (2005) 263-270. https://doi.org/10.1002/ppap.200400092.

[38] X. Shi, Y. Bin, D. Hou, M. Matsuo, Surface characterization for ultrahigh molecular weight polyethylene/hydroxyapatite gradient composites prepared by the gelation/crystallization method, ACS Appl. Mater. Interfaces. 5 (2013) 1768-1780. https://doi.org/10.1021/am3030504.

[39] S.A. Mirsalehi, A. Khavandi, S.H. Mirdamadi, M.R. Naimi-Jamal, S. Roshanfar, H. Fatehi-Peykani, Synthesis of nano-HA and the effects on the mechanical properties of HA/UHMWPE nanocomposites, Adv. Mater. Process. Technol. 2 (2016) 209-219. https://doi.org/10.1080/2374068X.2015.1127544.

[40] L. Fang, Y. Leng, P. Gao, Processing of hydroxyapatite reinforced ultrahigh molecular weight polyethylene for biomedical applications, Biomaterials. 26 (2005) 3471-3478. https://doi.org/10.1016/j.biomaterials.2004.09.022.

[41] Y.S. Zoo, J.W. An, D.P. Lim, D.S. Lim, Effect of carbon nanotube addition on tribological behavior of UHMWPE, Tribol. Lett. 16 (2004) 305-310. https://doi.org/10.1023/B:TRIL.0000015206.21688.87.

[42] C. Wolf, K. Lederer, R. Pfragner, K. Schauenstein, E. Ingolic, V. Siegl, Biocompatibility of ultra-high molecular weight polyethylene (UHMW-PE) stabilized with $\alpha$-tocopherol used for joint endoprostheses assessed in vitro, J. Mater. Sci. Mater. Med. 18 (2007) 1247-1252. https://doi.org/10.1007/s10856-006-0098-6.

[43] I.Y. Grubova, M.A. Surmeneva, V. V. Shugurov, N.N. Koval, I.I. Selezneva, S.M. Lebedev, R.A. Surmenev, Effect of Electron Beam Treatment in Air on Surface 
Properties of Ultra-High-Molecular-Weight Polyethylene, J. Med. Biol. Eng. 36 (2016) 440-448. https://doi.org/10.1007/s40846-016-0135-y.

[44] E.C. Preedy, E. Brousseau, S.L. Evans, S. Perni, P. Prokopovich, Adhesive forces and surface properties of cold gas plasma treated UHMWPE, Colloids Surfaces A Physicochem. Eng. Asp. 460 (2014) 83-89. https://doi.org/10.1016/j.colsurfa.2014.03.052.

[45] L. Lin, A.S. Argon, Structure and plastic deformation of polyethylene, J. Mater. Sci. 29 (1994) 294-323. https://doi.org/10.1007/BF01162485.

[46] S. Kurtz, UHMWPE handbook, 2004.

[47] J.R. McLaughlin, E.D. Rentfrow, S.P. James, K.R. Lee, G.P. Beauregard, Clinical wear of 63 ultrahigh molecular weight polyethylene acetabular components: Effect of starting resin and forming method, J. Biomed. Mater. Res. 48 (2002) 374-384. https://doi.org/10.1002/(sici)1097-4636(1999)48:3<374::aid-jbm23>3.0.co;2-o.

[48] S.M. Kurtz, O.K. Muratoglu, M. Evans, A.A. Edidin, Advances in the processing, sterilization, and crosslinking of ultra-high molecular weight polyethylene for total joint arthroplasty, Biomaterials. 20 (1999) 1659-1688. https://doi.org/10.1016/S01429612(99)00053-8.

[49] S.M. Kurtz, Chapter 2 - From Ethylene Gas to UHMWPE Component: The Process of Producing Orthopedic Implants, Third Edit, Elsevier Inc., 2009. https://doi.org/http://dx.doi.org/10.1016/B978-0-12-374721-1.00002-X.

[50] P.H. Geil, P.H. Geil, Powder Compaction, Sintering, and Rolling of Ultra High Molecular Weight Polyethylene and Its Composites, 1981. https://doi.org/10.1080/00222348108015307.

[51] A. Barnetson, P.R. Hornsby, Observations on the sintering of ultra-high molecular weight polyethylene (UHMWPE) powders, J. Mater. Sci. Lett. 14 (1995) 80-84. 
https://doi.org/10.1007/BF00456553.

[52] R.H. Olley, I.L. Hosier, D.C. Bassett, N.G. Smith, On morphology of consolidated UHMWPE resin in hip cups, Biomaterials. 20 (1999) 2037-2046.

https://doi.org/10.1016/S0142-9612(99)00107-6.

[53] R.P. Kusy, J.Q. Whitley, Use of a sequential extraction technique to determine the MWD of bulk UHMWPE, J. Appl. Polym. Sci. 32 (1986) 4263-4269. https://doi.org/10.1002/app.1986.070320337.

[54] H.L. Wagner, J.G. Dillon, Viscosity and molecular weight distribution of ultrahigh molecular weight polyethylene using a high temperature low shear rate rotational viscometer, J. Appl. Polym. Sci. 36 (1988) 567-582. https://doi.org/10.1002/app.1988.070360310.

[55] S.M. Kurtz, L. Pruitt, C.W. Jewett, R.P. Crawford, D.J. Crane, A.A. Edidin, The yielding, plastic flow, and fracture behavior of ultra-high molecular weight polyethylene used in total joint replacements, Biomaterials. 19 (1998) 1989-2003. https://doi.org/10.1016/S0142-9612(98)00112-4.

[56] N.N. Koval, Y.E. Kreindel, V.S. Tolkachyov, S. P.M., The efect of gas on the development of a vaccum arc with a hollow anode, IEEE Trans. Electr. Insul. 4 (1985) $19-21$.

[57] J.S. Chen, Z. Sun, P.S. Guo, Z.B. Zhang, D.Z. Zhu, H.J. Xu, Effect of ion implantation on surface energy of ultrahigh molecular weight polyethylene, J. Appl. Phys. 93 (2003) 5103-5108. https://doi.org/10.1063/1.1559943.

[58] D. Chow, M.L. Nunalee, D.W. Lim, A.J. Simnick, A. Chilkoti, Peptide-based biopolymers in biomedicine and biotechnology, Mater. Sci. Eng. R Reports. 62 (2008) 125-155. https://doi.org/10.1016/j.mser.2008.04.004.

[59] A. Fernández, A. Thompson, The inactivation of Salmonella by cold atmospheric 
plasma treatment, Food Res. Int. 45 (2012) 678-684.

https://doi.org/10.1016/j.foodres.2011.04.009.

[60] S. Perni, M.G. Kong, P. Prokopovich, Cold atmospheric pressure gas plasma enhances the wear performance of ultra-high molecular weight polyethylene, Acta Biomater. 8 (2012) 1357-1365. https://doi.org/10.1016/j.actbio.2011.12.007.

[61] A. Chug, S. Shukla, L. Mahesh, S. Jadwani, Osseointegration-Molecular events at the bone-implant interface: A review, J. Oral Maxillofac. Surgery, Med. Pathol. 25 (2013) 1-4. https://doi.org/10.1016/j.ajoms.2012.01.008.

[62] H. Gleiter, Improving the biocompatibility of medical implants with plasma immersion ion implantation, Prog. Mater. Sci. 33 (1989) 233. https://doi.org/10.1016/S02578972(02)00085-3.

[63] T.L. Schiller, D. Sheeja, D.R. McKenzie, D.G. McCulloch, D.S.P. Lau, S. Burn, B.K. Tay, Plasma immersion ion implantation of poly(tetrafluoroethylene), Surf. Coatings Technol. 177-178 (2004) 483-488. https://doi.org/10.1016/S0257-8972(03)00916-2.

[64] A. Turos, J. Jagielski, A. Piatkowska, D. Bieliński, L. Ślusarski, N.K. Madi, Ion beam modification of surface properties of polyethylene, User Model. User-Adapt. Interact. 70 (2003) 201-206. https://doi.org/10.1016/S0042-207X(02)00643-7.

[65] J.Y. Sze, B.K. Tay, Carbon ion implantation of ultra-high molecular weight polyethylene using filtered cathodic vacuum arc with substrate pulse biasing, Surf. Coatings Technol. 200 (2006) 4104-4110. https://doi.org/10.1016/j.surfcoat.2005.04.001.

[66] A. Valenza, A.M. Visco, L. Torrisi, N. Campo, Characterization of ultra-highmolecular-weight polyethylene (UHMWPE) modified by ion implantation, Polymer (Guildf). 45 (2004) 1707-1715. https://doi.org/10.1016/j.polymer.2003.12.056.

[67] Y. Bin, A. Yamanaka, Q. Chen, Y. Xi, X. Jiang, M. Matsuo, Morphological, electrical 
and mechanical properties of ultrahigh molecular weight polyethylene and multi-wall carbon nanotube composites prepared in decalin and paraffin, Polym. J. 39 (2007) 598-609. https://doi.org/10.1295/polymj.PJ2006229.

[68] E. Smolko, G. Romero, Studies on crosslinked hydroxyapatite-polyethylene composite as a bone-analogue material, Radiat. Phys. Chem. 76 (2007) 1414-1418. https://doi.org/10.1016/j.radphyschem.2007.02.043.

[69] X. Kang, W. Zhang, C. Yang, Mechanical properties study of micro- and nanohydroxyapatite reinforced ultrahigh molecular weight polyethylene composites, J. Appl. Polym. Sci. 133 (2016) 1-9. https://doi.org/10.1002/app.42869.

[70] B.S. Heidari, E. Oliaei, H. Shayesteh, S.M. Davachi, I. Hejazi, J. Seyfi, M. Bahrami, H. Rashedi, Simulation of mechanical behavior and optimization of simulated injection molding process for PLA based antibacterial composite and nanocomposite bone screws using central composite design, Elsevier, 2017. https://doi.org/10.1016/j.jmbbm.2016.08.008.

[71] F.S. Senatov, M. V. Gorshenkov, V. V. Tcherdyntsev, S.D. Kaloshkin, V.A. Sudarchikov, Fractographic analysis of composites based on ultra high molecular weight polyethylene, Compos. Part B Eng. 56 (2014) 869-875. https://doi.org/10.1016/j.compositesb.2013.08.083.

[72] J.W. Shim, Y.C. Nho, Preparation of Poly(acrylic acid)-Chitosan Hydrogels by Gamma Irradiation and In Vitro Drug Release, J. Appl. Polym. Sci. 90 (2003) 36603667. https://doi.org/10.1002/app.13120.

[73] M.A. Yessine, J.C. Leroux, Membrane-destabilizing polyanions: Interaction with lipid bilayers and endosomal escape of biomacromolecules, Adv. Drug Deliv. Rev. 56 (2004) 999-1021. https://doi.org/10.1016/j.addr.2003.10.039.

[74] B. Gupta, J.G. Hilborn, I. Bisson, P. Frey, Plasma-Induced Graft Polymerization of 
Acrylic Acid onto Poly(ethylene terepthalate) Films, (2001) 2993-3001.

[75] Y. Deng, D. Xiong, K. Wang, Biotribological properties of UHMWPE grafted with AA under lubrication as artificial joint, J. Mater. Sci. Mater. Med. 24 (2013) 20852091. https://doi.org/10.1007/s10856-013-4970-x.

[76] A.L.L. Oliveira, R.G. Lima, E.G. Cueva, R.D. Queiroz, Comparative analysis of surface wear from total hip prostheses tested on a mechanical simulator according to standards ISO 14242-1 and ISO 14242-3, Wear. 271 (2011) 2340-2345. https://doi.org/10.1016/j.wear.2011.01.062.

[77] M.P. Gispert, A.P. Serro, R. Colaço, A.M.B. do Rego, E. Alves, R.C. da Silva, P. Brogueira, E. Pires, B. Saramago, Tribological behaviour of Cl-implanted TiN coatings for biomedical applications, Wear. 262 (2007) 1337-1345. https://doi.org/10.1016/j.wear.2007.01.017.

[78] T. Aizawa, A. Mitsuo, T. Akhadejdamrong, Chemical Modification of Titanium Nitride Films via Ion Implantation, Mater. Trans. 44 (2005) 1962-1970. https://doi.org/10.2320/matertrans.44.1962.

[79] R. Lappalainen, H. Heinonen, A. Anttila, S. Santavirta, Some relevant issues related to the use of amorphous diamond coatings for medical applications, Diam. Relat. Mater. 7 (1998) 482-485. https://doi.org/10.1016/s0925-9635(98)80003-4.

[80] V.M. Tiainen, Amorphous carbon as a bio-mechanical coating-mechanical properties and biological applications, Diam. Relat. Mater. 10 (2001) 153-160. https://doi.org/10.1016/S0925-9635(00)00462-3.

[81] V.N. Inkin, G.G. Kirpilenko, A.A. Dementjev, K.I. Maslakov, A superhard diamondlike carbon film, Diam. Relat. Mater. 9 (2000) 715-721. https://doi.org/10.1016/S0925-9635(99)00344-1.

[82] W.C. Oliver, G.M. Pharr, An improved technique for determining hardness and elastic 
modulus using load and displacement sensing indentation experiments, J. Mater. Res. 7 (1992) 1564-1583. https://doi.org/10.1557/JMR.1992.1564.

[83] L. Melk, N. Emami, Mechanical and thermal performances of UHMWPE blended vitamin E reinforced carbon nanoparticle composites, Compos. Part B Eng. 146 (2018) 20-27. https://doi.org/10.1016/j.compositesb.2018.03.034.

[84] J. Fu, J. Shen, G. Gao, Y. Xu, R. Hou, Y. Cong, Y. Cheng, Natural polyphenolstabilised highly crosslinked UHMWPE with high mechanical properties and low wear for joint implants, J. Mater. Chem. B. 1 (2013) 4727-4735. https://doi.org/10.1039/c3tb20707b.

[85] N. Tomita, T. Kitakura, N. Onmori, Y. Ikada, E. Aoyama, Prevention of fatigue cracks in ultrahigh molecular weight polyethylene joint components by the addition of vitamin E, J. Biomed. Mater. Res. 48 (1999) 474-478. https://doi.org/10.1002/(SICI)1097-4636(1999)48:4<474::AID-JBM11>3.0.CO;2-T.

[86] C. Wolf, K. Lederer, U. Müller, Tests of biocompatibility of $\alpha$-tocopherol with respect to the use as a stabilizer in ultrahigh molecular weight polyethylene for articulating surfaces in joint endoprostheses, J. Mater. Sci. Mater. Med. 13 (2002) 701-705. https://doi.org/10.1023/A:1015750112343.

[87] F. Rupp, R.A. Gittens, L. Scheideler, A. Marmur, B.D. Boyan, Z. Schwartz, J. GeisGerstorfer, A review on the wettability of dental implant surfaces I: Theoretical and experimental aspects, Acta Biomater. 10 (2014) 2894-2906. https://doi.org/10.1016/j.actbio.2014.02.040.

[88] P.S.R. Sreekanth, S. Kanagaraj, In fl uence of multi walled carbon nanotubes reinforcement and gamma irradiation on the wear behaviour of UHMWPE, Wear. (2015) 1-9. https://doi.org/10.1016/j.wear.2014.12.014.

[89] N.N. Kumar, S.L. Yap, F.N.D. bt Samsudin, M.Z. Khan, R.S.P. Srinivasa, Effect of 
argon plasma treatment on tribological properties of UHMWPE/MWCNT

nanocomposites, Polymers (Basel). 8 (2016) 1-15.

https://doi.org/10.3390/polym8080295.

[90] P.S. Rama Sreekanth, N. Naresh Kumar, S. Kanagaraj, Improving post irradiation stability of high density polyethylene by multi walled carbon nanotubes, Compos. Sci. Technol. 72 (2012) 390-396. https://doi.org/10.1016/j.compscitech.2011.11.031.

[91] H. Hu, G. Zhang, L. Xiao, H. Wang, Q. Zhang, Z. Zhao, Preparation and electrical conductivity of graphene/ultrahigh molecular weight polyethylene composites with a segregated structure, Carbon N. Y. 50 (2012) 4596-4599. https://doi.org/10.1016/j.carbon.2012.05.045.

[92] J. Wei, T. Igarashi, N. Okumori, T. Igarashi, T. Maetani, B. Liu, M. Yoshinari, Influence of surface wettability on competitive protein adsorption and initial attachment of osteoblasts, Biomed. Mater. 4 (2009) 1-7. https://doi.org/10.1088/1748$6041 / 4 / 4 / 045002$.

[93] D. Yarmolich, P. Nozar, S. Gleizer, Y.E. Krasik, G. Mittica, C. Ancora, A. Brillante, I. Bilotti, C. Taliani, Characterization of deposited films and the electron beam generated in the pulsed plasma deposition gun, Jpn. J. Appl. Phys. 50 (2011) 1-5. https://doi.org/10.1143/JJAP.50.08JD03.

[94] M. Bianchi, A. Gambardella, M. Berni, S. Panseri, M. Montesi, N. Lopomo, A. Tampieri, M. Marcacci, A. Russo, Surface morphology, tribological properties and in vitro biocompatibility of nanostructured zirconia thin films, J. Mater. Sci. Mater. Med. 27 (2016) 1-10. https://doi.org/10.1007/s10856-016-5707-4.

[95] C.F. Gutiérrez-González, J.F. Bartolomé, Tribological behavior of a novel alumina/nano-zirconia/niobium biocomposite against ultra high molecular weight polyethylene, Wear. 303 (2013) 211-215. https://doi.org/10.1016/j.wear.2013.03.015. 
[96] S. Ge, Q. Wang, D. Zhang, H. Zhu, D. Xiong, C. Huang, X. Huang, Friction and wear behavior of nitrogen ion implanted UHMWPE against ZrO2 ceramic, Wear. 255 (2003) 1069-1075. https://doi.org/10.1016/S0043-1648(03)00269-2.

[97] H. Unal, A. Mimaroglu, Influence of test conditions on the tribological properties of polymers, Ind. Lubr. Tribol. 55 (2003) 178-183.

https://doi.org/10.1108/00368790310480362.

[98] J.K. Keum, F. Zuo, B.S. Hsiao, Formation and stability of shear-induced shish-kebab structure in highly entangled melts of UHMWPE/HDPE blends, Macromolecules. 41 (2008) 4766-4776. https://doi.org/10.1021/ma800063e.

[99] O.O. Mykhaylyk, P. Chambon, R.S. Graham, J.P.A. Fairclough, P.D. Olmsted, A.J. Ryan, The specific work of flow as a universal parameter to control the formation of Shish-Kebab morphology in polymers, AIP Conf. Proc. 1027 (2008) 496-498. https://doi.org/10.1063/1.2964741.

[100] J. Fu, B.W. Ghali, A.J. Lozynsky, E. Oral, O.K. Muratoglu, Ultra high molecular weight polyethylene with improved plasticity and toughness by high temperature melting, Polymer (Guildf). 51 (2010) 2721-2731. https://doi.org/10.1016/j.polymer.2010.04.003.

[101] L. Xiong, D. Xiong, The influence of irradiation dose on mechanical properties and wear resistance of molded and extruded ultra high molecular weight polyethylene, J. Mech. Behav. Biomed. Mater. 9 (2012) 73-82. https://doi.org/10.1016/j.jmbbm.2012.01.002.

[102] H. Fouad, R. Elleithy, High density polyethylene/graphite nano-composites for total hip joint replacements: Processing and in vitro characterization, J. Mech. Behav. Biomed. Mater. 4 (2011) 1376-1383. https://doi.org/10.1016/j.jmbbm.2011.05.008. [103] T. V. Zhil'tsova, M.S.A. Oliveira, J.A.F. Ferreira, Relative influence of injection 
molding processing conditions on HDPE acetabular cups dimensional stability, J.

Mater. Process. Technol. 209 (2009) 3894-3904.

https://doi.org/10.1016/j.jmatprotec.2008.09.018.

[104] Y.F. Huang, J.Z. Xu, J.Y. Xu, Z.C. Zhang, B.S. Hsiao, L. Xu, Z.M. Li, Self-reinforced polyethylene blend for artificial joint application, J. Mater. Chem. B. 2 (2014) 971980. https://doi.org/10.1039/c3tb21231a.

[105] Y.F. Huang, J.Z. Xu, J.S. Li, B.X. He, L. Xu, Z.M. Li, Mechanical properties and biocompatibility of melt processed, self-reinforced ultrahigh molecular weight polyethylene, Biomaterials. 35 (2014) 6687-6697. https://doi.org/10.1016/j.biomaterials.2014.04.077.

[106] K. Peters, H. Schmidt, R.E. Unger, M. Otto, G. Kamp, C.J. Kirkpatrick, Softwaresupported image quantification of angiogenesis in an in vitro culture system: Application to studies of biocompatibility, Biomaterials. 23 (2002) 3413-3419. https://doi.org/10.1016/S0142-9612(02)00042-X.

[107] A. Dorner-Reisel, C. Schürer, V. Klemm, G. Irmer, E. Müller, Nano- and microstructure of diamond-like carbon films modified by Ca-O incorporation, Diam. Relat. Mater. 12 (2003) 1030-1033. https://doi.org/10.1016/S0925-9635(02)00293-5.

[108] A. Dorner, C. Schürer, G. Reisel, G. Irmer, O. Seidel, E. Müller, Diamond-like carboncoated Ti6A14V: Influence of the coating thickness on the structure and the abrasive wear resistance, Wear. 249 (2001) 489-497. https://doi.org/10.1016/S00431648(01)00587-7.

[109] A. Dorner-Reisel, C. Schürer, E. Müller, The wear resistance of diamond-like carbon coated and uncoated Co28Cr6Mo knee prostheses, Diam. Relat. Mater. 13 (2004) 823827. https://doi.org/10.1016/j.diamond.2003.11.080.

[110] A. Visco, S. Yousef, G. Galtieri, D. Nocita, A. Pistone, J. Njuguna, Thermal, 
Mechanical and Rheological Behaviors of Nanocomposites Based on UHMWPE/Paraffin Oil/Carbon Nanofiller Obtained by Using Different Dispersion Techniques, Jom. 68 (2016) 1078-1089. https://doi.org/10.1007/s11837-016-1845-x.

[111] J.C.M. Suarez, R.S. De Biasi, Effect of gamma irradiation on the ductile-to-brittle transition in ultra-high molecular weight polyethylene, Polym. Degrad. Stab. 82 (2003) 221-227. https://doi.org/10.1016/S0141-3910(03)00212-X.

[112] S. Yousef, A. Visco, G. Galtieri, D. Nocita, C. Espro, Wear behaviour of UHMWPE reinforced by carbon nanofiller and paraffin oil for joint replacement, Mater. Sci. Eng. C. 73 (2017) 234-244. https://doi.org/10.1016/j.msec.2016.11.088.

[113] W.H. Zhong, G. Sui, S. Jana, J. Miller, Cosmic radiation shielding tests for UHMWPE fiber/nano-epoxy composites, Compos. Sci. Technol. 69 (2009) 2093-2097. https://doi.org/10.1016/j.compscitech.2008.10.004.

[114] Y. Chen, Y. Qi, Z. Tai, X. Yan, F. Zhu, Q. Xue, Preparation, mechanical properties and biocompatibility of graphene oxide/ultrahigh molecular weight polyethylene composites, Eur. Polym. J. 48 (2012) 1026-1033. https://doi.org/10.1016/j.eurpolymj.2012.03.011.

[115] M.R. Davidson, S.A. Mitchell, R.H. Bradley, Surface studies of low molecular weight photolysis products from UV-ozone oxidised polystyrene, Surf. Sci. 581 (2005) 169177. https://doi.org/10.1016/j.susc.2005.02.049.

[116] A.H.C. Poulsson, S.A. Mitchell, M.R. Davidson, A.J. Johnstone, N. Emmison, R.H. Bradley, Attachment of Human Primary Osteoblast Cells to Modified Polyethylene Surfaces, Langmuir. 25 (2009) 3718-3727. https://doi.org/10.1021/la801820s.

[117] Y. Shikinami, H. Kawarada, Potential application of a triaxial three-dimensional fabric (3-DF) as an implant, Biomaterials. 19 (1998) 617-635. https://doi.org/10.1016/S0142-9612(97)00152-X. 
[118] R. Langer, C.L. Mazzoni, C. Breuer, J.P. Vacanti, D.J. Mooney, D. Hern, K. McNamara, Stabilized polyglycolic acid fibre-based tubes for tissue engineering, Biomater. Silver Jubil. Compend. 17 (2008) 129-138. https://doi.org/10.1016/b978008045154-1.50017-4.

[119] K.C. Baker, M.A. Anderson, S.A. Oehlke, A.I. Astashkina, D.C. Haikio, J. Drelich, S.W. Donahue, Growth, characterization and biocompatibility of bone-like calcium phosphate layers biomimetically deposited on metallic substrata, Mater. Sci. Eng. C. 26 (2006) 1351-1360. https://doi.org/10.1016/j.msec.2005.08.015.

[120] A. Reising, C. Yao, D. Storey, T.J. Webster, Greater osteoblast long-term functions on ionic plasma deposited nanostructured orthopedic implant coatings, J. Biomed. Mater. Res. - Part A. 87 (2008) 78-83. https://doi.org/10.1002/jbm.a.31772.

[121] A. Gupta, G. Tripathi, D. Lahiri, K. Balani, Compression Molded Ultra High Molecular Weight Polyethylene-Hydroxyapatite-Aluminum Oxide-Carbon Nanotube Hybrid Composites forHard Tissue Replacement, J. Mater. Sci. Technol. 29 (2013) 514-522. https://doi.org/10.1016/j.jmst.2013.03.010.

[122] A.J. Nathanael, D. Mangalaraj, P. Chi Chen, N. Ponpandian, Enhanced mechanical strength of hydroxyapatite nanorods reinforced with polyethylene, J. Nanoparticle Res. 13 (2011) 1841-1853. https://doi.org/10.1007/s11051-010-9932-3.

[123] L.M. Rodríguez-Lorenzo, M. Vallet-Regí, Controlled crystallization of calcium phosphate apatites, Chem. Mater. 12 (2000) 2460-2465. https://doi.org/10.1021/cm001033g.

[124] C. Meng, Y. Chen, M. Xie, Z. Yu, B. Yang, Surface modification of ultrahigh molecular weight polyethylene by plasma-induced in-situ grafting with vinyl triethoxysilane, J. Biomed. Mater. Res. - Part A. 106 (2018) 321-332. https://doi.org/10.1002/jbm.a.36241. 
[125] J. Esteban, R. Pérez-Tanoira, C. Pérez-Jorge-Peremarch, E. Gómez-Barrena, Bacterial Adherence to Biomaterials Used in Surgical Procedures, Microbiol. Surg. Infect. Diagnosis, Progn. Treat. (2014) 41-57. https://doi.org/10.1016/B978-0-12-4116290.00003-9.

[126] M. Mohanty, T. V. Kumary, A. V. Lal, R. Sivakumar, Short term tissue response to carbon fibre: A preliminary in vitro and in vivo study, Bull. Mater. Sci. 21 (1998) 439444. https://doi.org/10.1007/BF02790343.

[127] R. Neugebauer, G. Helbing, D. Wolter, W. Mohr, G. Gistinger, The body reaction to carbon fibre particles implanted into the medullary space of rabbits, Biomaterials. 2 (1981) 182-184. https://doi.org/10.1016/0142-9612(81)90049-1.

[128] J. Lawrence, L. Li, Wettability characteristics of polyethylene modified with $\mathrm{CO}<\mathrm{SUB}>2</ \mathrm{SUB}>, \mathrm{Nd}: \mathrm{YAG}$, excimer and high-power diode lasers, Proc. I MECH E Part B J. Eng. Manuf. 215 (2001) 1735-1744.

https://doi.org/10.1243/0954405011519556.

[129] A. Lorusso, V. Nassisi, F. Paladini, L. Torrisi, A.M. Visco, N. Campo, Comparison of the laser effects induced on ultra-high-molecular-weight polyethylene, Radiat. Eff. Defects Solids. 163 (2008) 435-440. https://doi.org/10.1080/10420150701778155.

[130] Y. Lin, J. Jin, M. Song, Preparation and characterisation of covalent polymer functionalized graphene oxide, J. Mater. Chem. 21 (2011) 3455-3461. https://doi.org/10.1039/c0jm01859g.

[131] M. Maniruzzaman, J.S. Boateng, M.J. Snowden, D. Douroumis, A Review of HotMelt Extrusion: Process Technology to Pharmaceutical Products, ISRN Pharm. 2012 (2012) 1-9. https://doi.org/10.5402/2012/436763.

[132] S.A. Bhusari, V. Sharma, S. Bose, B. Basu, HDPE/UHMWPE hybrid nanocomposites with surface functionalized graphene oxide towards improved strength and 
cytocompatibility, J. R. Soc. Interface. 16 (2019) 1-16.

https://doi.org/10.1098/rsif.2018.0273.

[133] Y. Yang, A.M. Asiri, Z. Tang, D. Du, Y. Lin, Graphene based materials for biomedical applications, Mater. Today. 16 (2013) 365-373.

https://doi.org/10.1016/j.mattod.2013.09.004.

[134] H.S. Jaggi, S. Kumar, D. Das, B.K. Satapathy, A.R. Ray, Morphological correlations to mechanical performance of hydroxyapatite-filled HDPE/UHMWPE composites, J. Appl. Polym. Sci. 132 (2014) 1-10. https://doi.org/10.1002/app.41251.

[135] J. Reis, S. Kanagaraj, A. Fonseca, M.T. Mathew, F. Capela-Silva, J. Potes, A. Pereira, M.S.A. Oliveira, J.A. Simões, In vitro studies of multiwalled carbon nanotube/ultrahigh molecular weight polyethylene nanocomposites with osteoblastlike MG63 cells, Brazilian J. Med. Biol. Res. 43 (2010) 476-482.

https://doi.org/10.1590/S0100-879X2010007500038.

[136] P. Sarkar, D. De, H. Rho, Synthesis and microstructural manipulation of ceramics by electrophoretic deposition, J. Mater. Sci. 39 (2004) 819-823. https://doi.org/10.1023/B:JMSC.0000012909.46419.0e.

[137] M. Li, Q. Liu, Z. Jia, X. Xu, Y. Cheng, Y. Zheng, T. Xi, S. Wei, Graphene oxide/hydroxyapatite composite coatings fabricated by electrophoretic nanotechnology for biological applications, Carbon N. Y. 67 (2014) 185-197. https://doi.org/10.1016/j.carbon.2013.09.080. 


\section{Declaration of interests}

$\bigotimes$ The authors declare that they have no known competing financial interests or personal relationships that could have appeared to influence the work reported in this paper.

$\square$ The authors declare the following financial interests/personal relationships which may be considered as potential competing interests:

\section{Graphical Abstract}




\section{Journal Pre-proofs}

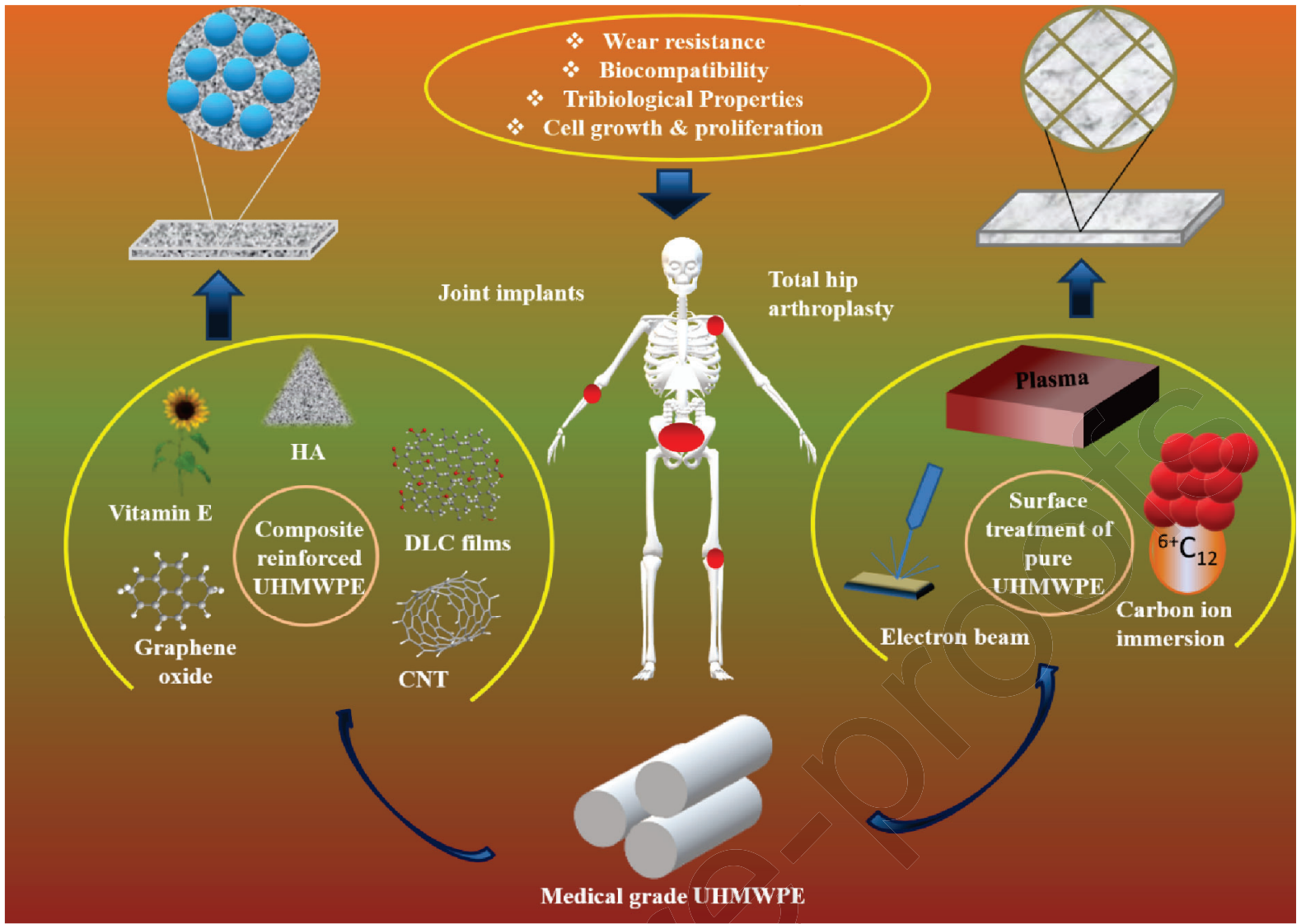

